TI 2017-084/VIII

Tinbergen Institute Discussion Paper
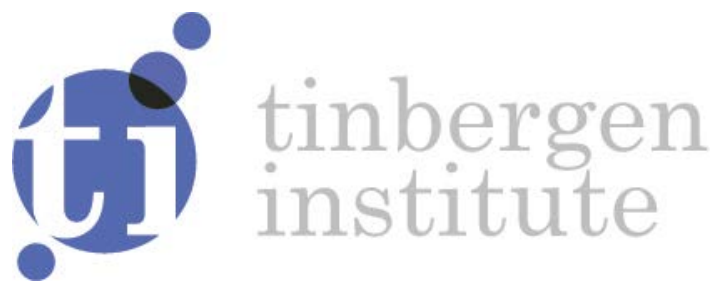

\title{
The Financial Crisis and Diverging House Prices: Evidence from the Copenhagen Metropolitan Area
}

Ismir Mulalic ${ }^{1,2}$

Holger Rasmussen ${ }^{1}$

Jan Rouwendal ${ }^{3}$

Hans Henrik Woltmann ${ }^{1}$

${ }^{1}$ Kraks Fond - Institute for Urban Economic Research, Denmark

2 Technical University of Denmark

${ }^{3}$ Vrije Universiteit Amsterdam; Tinbergen Institute, The Netherlands 
Tinbergen Institute is the graduate school and research institute in economics of Erasmus University Rotterdam, the University of Amsterdam and VU University Amsterdam.

Contact: discussionpapers@tinbergen.nl

More TI discussion papers can be downloaded at http://www.tinbergen.nl

Tinbergen Institute has two locations:

Tinbergen Institute Amsterdam

Gustav Mahlerplein 117

1082 MS Amsterdam

The Netherlands

Tel.: $+31(0) 205984580$

Tinbergen Institute Rotterdam

Burg. Oudlaan 50

3062 PA Rotterdam

The Netherlands

Tel.: +31(0)10408 8900 


\title{
The Financial Crisis and Diverging House Prices: Evidence from the Copenhagen Metropolitan Area
}

\author{
Ismir Mulalic $^{1,2}$, Holger Rasmussen ${ }^{1}$, Jan Rouwendal ${ }^{3}$ and Hans Henrik Woltmann ${ }^{1}$
}

This version: 24/08/2017.

\begin{abstract}
This paper investigates the development of house prices in Copenhagen in the period 1994-2013, while paying special attention to the heterogeneous impact of the boom and bust periods along the dimensions of housing type (single vs multifamily housing), geography and quality. To allow for price developments that can differ by quality, we use a recently developed generalization of the conventional Muth model that assumes a constant unit price across the quality spectrum. It allows us to separately consider the development of house prices and quality in Copenhagen neighbourhoods. Moreover, we investigate the validity of the common assumption of a constant unit price and reject it decisively. We use detailed housing transaction data for the greater Copenhagen area. We show that the housing boom of the 2000's and the bust that followed hit the lowest quality segments significantly harder than the high quality segments of the housing market.
\end{abstract}

Keywords: housing price, housing quality, housing price index.

JEL codes: D40, L85, R21, R31.

\section{Acknowledgement}

The authors thank to Statistics Denmark for providing the data. Research support from Kraks Fond - Institute for Urban Economic Research is gratefully acknowledged. The usual disclaimer applies.

${ }^{1}$ Kraks Fond - Institute for Urban Economic Research, Frederiksholms Kanal 30, DK-1220 Copenhagen K, Denmark.

${ }^{2}$ DTU Management Engineering, Technical University of Denmark, Produktionstorvet, building 426, DK-2800 Kgs. Lyngby, Denmark.

${ }^{3}$ Department of Spatial Economics, Vrije Universiteit Amsterdam, De Boelelaan 1105, $1081 \mathrm{HV}$ Amsterdam, and Tinbergen Institute, Gustav Mahlerplein 117, 1082 MS Amsterdam, The Netherlands. 



\section{Introduction}

This paper studies the development of the housing market in the Greater Copenhagen Area (GCA) over the period 1994-2013. The focus is on the financial crises that started in 2007 in the US and developed into a worldwide recession that hit Europe particularly hard. Denmark was no exception.

Housing is the most important asset for many households and the housing stock is often the largest asset of a country. ${ }^{1}$ The profitability of many businesses is directly tied to the housing market, with real estate agents, banks and the construction industry as the most prominent examples. According to many, house price developments also have a large impact on consumption (see e.g. Piazzesi and Schneider, 2016). The housing market not only undergoes economic shocks, such as the implication of the financial crisis for the availability of mortgage loans, but plays a role in their transmission in the wider economy. This makes the study of the housing markets interesting from a wider perspective (see Piazzesi and Schneider, 2016; Davis and Van Nieuwerburgh, 2014).

In the course of the time window we study the GCA, and in particular the city of Copenhagen, transformed from an unattractive and cramped area in the beginning of the 1990's, into the most popular place to live in Denmark 15 years after. ${ }^{2}$ The massive investment in renovation in the 90's which involved installing bathrooms and toilets in many apartments and tearing down back alley houses strongly improved the attractiveness of the GCA. Moreover, during the 1990's the number of jobs in the service sector in Copenhagen increased by 30\%, while the number of manufacturing jobs decreased to half of what it was at the end of the eighties (Bisgaard, 2010). The bridge to Sweden, across the Sound (Øresundsbroen) opened in 2000 and the Copenhagen Metro (a rapid transit system) serving four municipalities in the GCA opened in three phases between 2002 and 2007. The massive investment in housing in the first decade of 2000's resulted in significant increase in high quality housing that also very likely had a significant impact on housing prices.

\footnotetext{
${ }^{1}$ The households' expenses, assets and debts are to a large degree made up by housing. In Denmark, housing assets accounted for roughly $50 \%$ of household wealth and mortgage backed loans accounted for roughly $75 \%$ of household debt in 2014.

${ }^{2}$ See Bisgaard (2010) for a detailed analysis of the evolution of the city of Copenhagen.
} 
There is considerable evidence that various segments of the housing market develop in different ways. Ortalo-Magné and Rady (2006) show that the relaxation of credit constraints associated with a down payment constraint may accelerate the demand for runner-up homes during an economic upswing, which may lead to strong increases in demand and above-average price increases for such houses. Guerrieri et al. (2013) show that within an urban area neighborhoods can have significantly different price developments. Piazzesi et al. (2007) argues that a half of the volatility in individual house prices is city-level variation, while one quarter of the individual volatility is aggregate house price variation. This illustrates the importance to understand the variation in the housing price within narrow locations or individual houses. Liu et al. (2014) show that during the housing bust of the late 2000s in the US price developments were related to the size of the houses and could differ substantially. All this suggests that it will not be sufficient to describe the development of house prices for the whole area by a single number (a price index) for each period as is common. We analyse diverging house prices using the novel approach developed by Rouwendal and van Duijn (2015).

The approach we use separates the measurement of quality from that of the price and allows for quality-dependent price development. Taking quality aspects into account when studying the development of the housing price is desirable. ${ }^{3}$ The housing stock is heterogeneous and since only a small fraction of it is sold at a given point in time, changes in the composition of the sold houses can be misinterpreted as price fluctuations (Hill, 2011). ${ }^{4}$ McMillen (2008) argues that changes in the types of houses sold and their location have a significant impact on the apparently higher appreciation rates for relatively high-price houses. The objective of this paper is to develop a deeper understanding of price and quality dispersion on the Copenhagen housing market in recent decades.

Based on the administrative register data on all realized real estate transactions within the GCA for the period 1993-2014, we first construct a one-dimensional measure of house quality and then estimate price indices for a range of different quality segments. We test the validity of

\footnotetext{
${ }^{3}$ Hviid (2017) develops a fundamentals-adjusted house price index for Denmark, which adjusts for evolving income, housing stock, and user costs in order to isolate the effects of a house-price bubble. However, in this index price differences are always proportional to quality differences, which excludes the heterogeneity in price developments among housing segments.

${ }^{4}$ The observed transactions at the housing market do not necessarily represent a random sample from the total housing stock.
} 
the assumption of a constant unit price using a novel method and reject it decisively. We also show that the financial crisis from 2009 and onwards had a very different impact on the low and high quality housing segments.

The paper is organized as follows. The next section introduces the applied methodology. Section 3 provides information on the data employed; Section 4 presents the empirical results; Section 5 concludes.

\section{Methodology}

This section discusses the theory that underlies the empirical work that follows. We first show in sub-section 2.1. that differences in housing prices are related to differences in housing quality for a given market and that the evolution of price differences does not need to be proportional to the evolution of quality differences. Sub-section 2.2 describes the estimation of the price index for different segments of housing market.

\subsection{A generalization of Muth's model and hedonic analysis}

We follow Rouwendal and van Duijn (2015) and assume that house price is a function of the quality of housing $\mathrm{H}()$, and location, s:

$$
\mathrm{P}(\mathrm{s}, \mathbf{x})=\mathrm{F}(\mathrm{s}, \mathrm{H}(\mathbf{x})) \#(1)
$$

where $\mathbf{x}$ is vector of housing attributes. $H$ is a scalar indicator of quality, expressed as a function of housing characteristics. This one-dimensional quality index orders houses from low to high qualities. Housing quality enters thus the housing price function $F$ as a scalar. We assume that the price of a house, $P$, is a monotone increasing function, $F$, of the amount of housing service. The impact of $s$ reflects local amenities. ${ }^{5}$

The constant unit price assumption introduced by Muth (1960) that has become standard in economic analyses of the housing market is imposed by further specifying $\mathrm{F}$ as

$$
P=\Pi(s) H(\boldsymbol{x}) \#(2)
$$

where $\Pi$ is the unit price of housing quality. According to this simple model price differences are always proportional to quality differences, which excludes the heterogeneity in price

\footnotetext{
${ }^{5}$ In Muth (1966) housing quality is also expressed as a single number on a one-dimensional axis of quality. Epple et al. (2015) characterize housing units by a one-dimensional ordinal measure of quality.
} 
developments among housing segments that has been demonstrated to be an important aspects of actual housing markets. ${ }^{6}$

The conventional hedonic approach follows from (2). Adopting a log-linear representation of $\mathrm{H}$ implies:

$$
\mathrm{H}=\exp \left(\sum_{\mathrm{k}} \beta_{\mathrm{k}} \mathrm{X}_{\mathrm{k}}+\xi\right) \#(3)
$$

where $\mathrm{X}_{\mathrm{k}}$ is the $\mathrm{k}$-th of observable characteristics, $\xi$ is the unobservable characteristic and $\beta$ 's are coefficients. Substituting eq. (3) into eq. (2) and taking logs we get the familiar hedonic regression for a given market at a given time:

$$
\ln (\mathrm{P})=\ln (\Pi)+\sum_{\mathrm{k}} \beta_{\mathrm{k}} \mathrm{X}_{\mathrm{k}}+\xi \#(4)
$$

This model can be easily estimated using e.g. regression techniques. The estimated $\beta$ coefficients are then the shadow price estimates and the constant term $\ln (\Pi)$ represents the unit price. The market-specific and time-specific intercepts provide then a housing price index.

The approach adopted here differs from the hedonic in that we do not impose (2), and avoid further specification of the function $F{ }^{7}$ Apart from this, we stay close to the hedonic approach, and we maintain the loglinear specification (3) for housing quality. The only difference between the approach adopted here and the conventional Muth-approach is that we allow the marginal price of quality $\partial F / \partial H$ to be an arbitrary function of $s$ and $H$, whereas the conventional approach assumes it is a constant for given $s$.

\subsection{Estimating the housing price index}

Although the deviation from the familiar Muth model proposed here is relatively modest, it implies that we cannot use a specification like (4) to investigate price and quality aspects of housing. We follow Rouwendal and van Duijn (2015) and first estimate the housing service function $\mathrm{H}$ as specified in (3) and use the result to estimate $\mathrm{F}$ as specified in (1). In what follows we suppress the index s for notational simplicity.

\footnotetext{
${ }^{6}$ Note that this assumption arises from the zero intercept in the equation above.

${ }^{7}$ Piazzesi and Schneider (2016) suggest that linear pricing is too restrictive because volatility conditional on quality is high and because conditional means vary systematically by quality.
} 
Equation (1) implies that the ranking of houses based on their prices coincides with the ranking based on quality. If the price of house A is higher than the price of house B it is then, because the housing services of house A are superior to those of house B, formally: ${ }^{8}$

$$
\mathrm{P}_{\mathrm{A}}>\mathrm{P}_{\mathrm{B}} \Leftrightarrow \sum_{\mathrm{k}} \beta_{\mathrm{k}} \mathrm{X}_{\mathrm{Ak}}+\xi_{\mathrm{A}}>\sum_{\mathrm{k}} \beta_{\mathrm{k}} \mathrm{X}_{\mathrm{Bk}}+\xi_{\mathrm{B}} \text { \#(5) }
$$

Note that we include the unobserved quality aspects $\xi_{\mathrm{A}}$ and $\xi_{\mathrm{B}}$ in the comparison. If we assume that they are iid Extreme Value Type I distributed, we can find an expression for the probability that a particular ranking of houses is observed. ${ }^{9}$ More specifically, we can use the rank-ordered logit model originally formulated by Beggs et al. (1981) to estimate the parameters $\beta_{k}$ of the quality index in (3). These estimates can be used to construct the 'predicted' housing quality:

$$
\widehat{H}=\sum_{\mathrm{k}} \hat{\beta}_{k} X_{k}
$$

The next step is to estimate the function $F$ in (1). This can be done by any flexible regression method. Since the unobserved quality aspect $\xi$ is missing in the prediction, and $F$ may be nonlinear, we use the median regression.

\subsection{Testing the unit price hypothesis}

Since the approach adopted here generalizes a familiar and widely adopted practice, it is interesting to investigate the significance of the generalization. That is, we would like to know if the more involved approach that has just been proposed lead to results that differ significantly from the standard one. To do so, it is important to realize that the second inequality in (5) remains valid if we substitute $g\left(\sum_{\mathrm{k}} \beta_{\mathrm{k}} \mathrm{X}_{\mathrm{ik}}+\xi_{\mathrm{i}}\right), i=A, B$ for the expression on both sides of the inequality sign, where $g($.$) is an monotonically increasing function. This implies that we can$ only estimate housing services as an ordinal variable. Finding a nonlinear $F$ is therefore not sufficient to reject the constant unit price hypothesis. We must impose the more stringent requirement that the estimated function $F$ cannot be linearized by a monotonic transformation.

\footnotetext{
${ }^{8}$ This relation depends on the assumption of an increasing $\mathrm{F}(\cdot)$.

${ }^{9}$ The underlying assumption is that households agree on the ranking of all houses within the considered housing market. More importantly, households may differ in their taste for house quality relative to other consumption and consequently be willing to pay different amounts for any given house. For the more detailed discussion see Rouwendal and van Duijn (2015) and Piazzesi and Schneider (2016).
} 
We start by estimating the relation between our estimated quality measure, $\widehat{H}$, and house prices, $P$ :

$$
\ln (\mathrm{P})=\alpha \ln (\Pi)+\gamma \ln (\widehat{\mathrm{H}})+\varepsilon \#(7)
$$

We estimate the relation in equation (7) with the Conditionally Parametric Quantile Regression (CPAR) framework for a specific quality level over time. For the constant unit price assumption to hold, the return on quality for a specific quality level, $\gamma$, has to be constant over time. Moreover, the constant unit price assumption states that the return on quality should be the same for all quality levels. This implies that the partial derivative $\partial \ln (\mathrm{P}) / \partial \ln (\widehat{\mathrm{H}})$, so $\gamma$, should be constant for different quality levels for the constant unit price assumption to hold. ${ }^{10}$

\section{Institutional context, data and descriptives}

\subsection{The housing market in the Great Copenhagen Area}

Our analysis of the housing price and quality is based on Danish administrative register data on real estate transactions. Housing transactions are most likely influenced by the general economic climate, trends on the real estate market, but also the development of the regulatory framework. This section provides a short overview of the Great Copenhagen Area's real estate market as well as the most important regulatory factors that might affect housing sector.

The Danish housing sector is regulated through a number of measures including rent controls, real estate and land taxes, deductible interest payments, housing allowances and the provision of social housing. The degree of regulation differs by market segment (owneroccupied, privately rented and social housing). The owner-occupied housing sector is the least regulated (Erlandsen et al., 2006). ${ }^{11}$ However, regulations in the rental sector affect indubitably the owner-occupied housing sector as well. For instance, rigidities on the market for rental housing due to the rent controls and the presence of social housing have very likely a significant

\footnotetext{
${ }^{10}$ This test is different from the test proposed by Rouwendal and van Duijn (2015). They first estimate nonparametrically the log of the transaction price for any value of the housing services in any period using a local quantile (median) approach. The difference between the logarithms of the estimated prices for any two values of the housing services must be constant over time for the constant unit price assumption to hold. In the empirical section, we also test the constant unit price assumption using this test.

${ }^{11}$ The share of owner-occupied dwellings in the GCA in 2012 was only $20.5 \%$ compared to $51.3 \%$ in whole Denmark, see Statistics Denmark, 2016. BOL101: Dwellings by region, type of resident, use, tenure, owneroccupied flat, ownership and year of construction. Retrieved from http://statbank.dk/BOL101.
} 
spillover effect on segments of the owner-occupied housing market that are substitues for rental housing.

The wide-ranging regulation of the housing sector originates from the years immediately after WW2, when the Danish government reacted to shortages of dwellings by introducing strict rent controls and by subsidizing all kinds of housing construction. In later years, and especially after the oil crises in the 1970s, the housing sector has gradually become somewhat more liberalized. The development of housing policy was driven by changing political priorities of governments (e.g. expansions of social housing) and reactions to global economic trends. ${ }^{12}$ However, the current degree of regulation is still very high and although the owneroccupied housing sector is least regulated, it is still strongly affected by the high degree of regulation in the social rental sector. For example, in a situation of the excess demand on the housing market the housing price will not react optimally to price pressure due to the rent regulations. More importantly, excess demand will divert the price pressure almost exclusively on the less regulated segments of the market, i.e. the owner-occupied housing sector. As a result, while rent control is successful at smoothing price developments for accommodation in the regulated part of the housing stock, it might increase price volatility in the less regulated parts of the market, in particular those that offer close substitutes. ${ }^{13}$

Changes in economic growth, unemployment, wages and interest rates also affect housing market. The most recent big cycle started in 1993 and led to an exceptional uninterrupted sequence of 14 years with rising prices, see Figure 1. Part of this price increase can be attributed to the release of the interest-only loans that increased borrowing possibilities for households wanting to buy a house. The price peak was reached in early $2007 .{ }^{14}$ After this year prices fell sharply until mid-end 2009, and stabilized in the time afterwards. Ever since mid-2012 there is again a strong upwards trend, especially for multifamily houses. Figure 1 also shows that price movements of single family and multifamily houses were closely aligned, but not identical throughout the considered period.

\footnotetext{
${ }^{12}$ For a more exhaustive review of the history of the regulations see Vestergaard (2007).

${ }^{13}$ Munch and Svarer (2002) show that on average households in Denmark stayed six years longer in dwellings belonging to the $10 \%$ most regulated housing stock in the private rental sector as compared with households renting dwellings of the $10 \%$ least regulated part of the housing stock.

${ }^{14}$ According to Skaarup and Bødker (2010) the price increases until 2004 were completely justified by improving economic fundamentals. While fundamentals continued to improve after 2004, they improved not as fast as to justify the increased speed at which prices were rising in the following two years.
} 
Furthermore, until 2001, the Danish property tax was a fraction of a public valuation of the property, which was updated every second year. In 2001, the property taxation scheme changed so that the property tax was always a fraction of the 2001-valuation of the property, so the property tax from 2001 is a fixed nominal value, and was thus decoupled from any future price developments. Finally, the considered time period (1994-2013) covers various stages of a housing boom-bust cycle and few adjustments of the housing market regulation on top of an underlying trend that increased the attractiveness of the GCA.

\section{Figure 1: Housing price index for years 1994-2015}

120

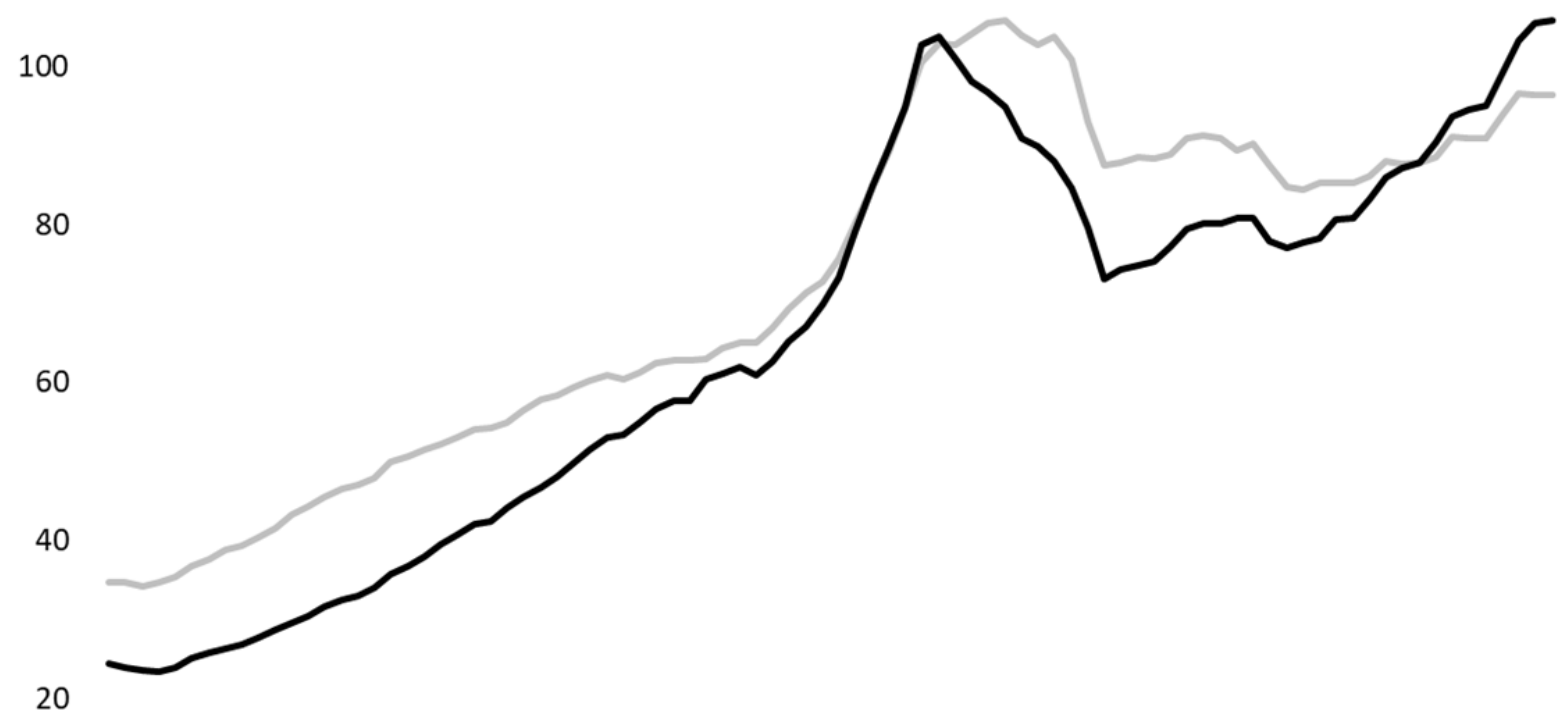

0

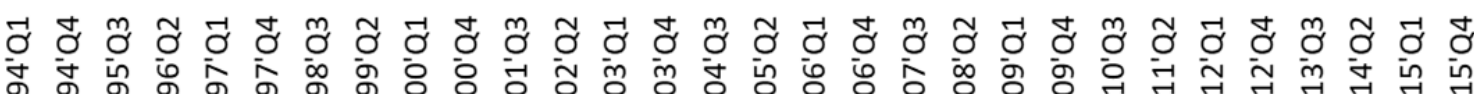
Apartment price index $(2006=100) \quad-$ House price index $(2006=100)$

\subsection{Sample selections and descriptives}


The administrative register data on realized real estate transactions, i.e. information on the price paid for specific dwellings, for the period 1994-2013, that we use here is of high quality relative to information reported by real estate agents or self-reported estimates of owner occupiers in census data (see e.g. Zabel and Kiel, 2000 and Bajari and Kahn, 2005) that are often used in empirical housing market research. ${ }^{15}$

The focus is on the GCA. By restricting the analysis to single metropolitan area, we avoid the potentially confounding effect that interregional differences in productivity, wage and urban amenities can have through their influence on the spatial equilibrium (Roback, 1982; Kahn, 1995). The metropolitan area of Copenhagen can be considered to be one integrated labor market and one integrated housing market. ${ }^{16}$

We also restrict our focus to so-called arm's length (non-family) sales where the buyer acts as private individual (non-enterprise). ${ }^{17}$ Moreover we distinguish between multifamily houses and single-family houses and carry out separate analyses for both segments of the market. We remove dwellings sold at a price above 9 M DKK (2013 prices) as they are assumed to be outliers. This relatively high cut-off threshold for expensive dwellings is chosen since high prices can also carry valuable information. The final sample includes 249,524 realized real estate transactions. Figure 2 shows the average sales prices from our sample (before removing the $9+$ M sales) and macro figures provided by Statistics Denmark. The pictured price indices are more or less identical. This is important because we base our results up against a "naive" median price index. From this point on the average sales prices will not add up to the macro figures due to the removal our 9+ M sales, but because we focus on median prices, it will not make a difference for our conclusions.

\section{Figure 2: Computed house price index and the price statistics from Statistics Denmark}

\footnotetext{
${ }^{15}$ Several studies have analyzed how good homeowners are at estimating the value of their property. Kiel and Zabel (1999) find that errors in homeowners' estimation are on average 5\%, but not systematically related to house characteristics. Goodman and Ittner (1992) find larger biases and hence also recommend more caution when using home owner value estimates to estimate hedonic price functions.

${ }^{16}$ This assumption is common in the literature. Mulalic et al. (2016) made it for their analysis of the residential choice in the GCA. Epple and Sieg (1999) make this assumption for Boston Metropolitan Area. They all stress the importance of focusing on one metropolitan area only.

17 Taylor (2003) argues that transactions used in a hedonic analysis should be 'arms-length' transactions. Transactions among family members and transactions resulting from foreclosure auctions do not meet this criterion and will hence be excluded from the analysis.
} 


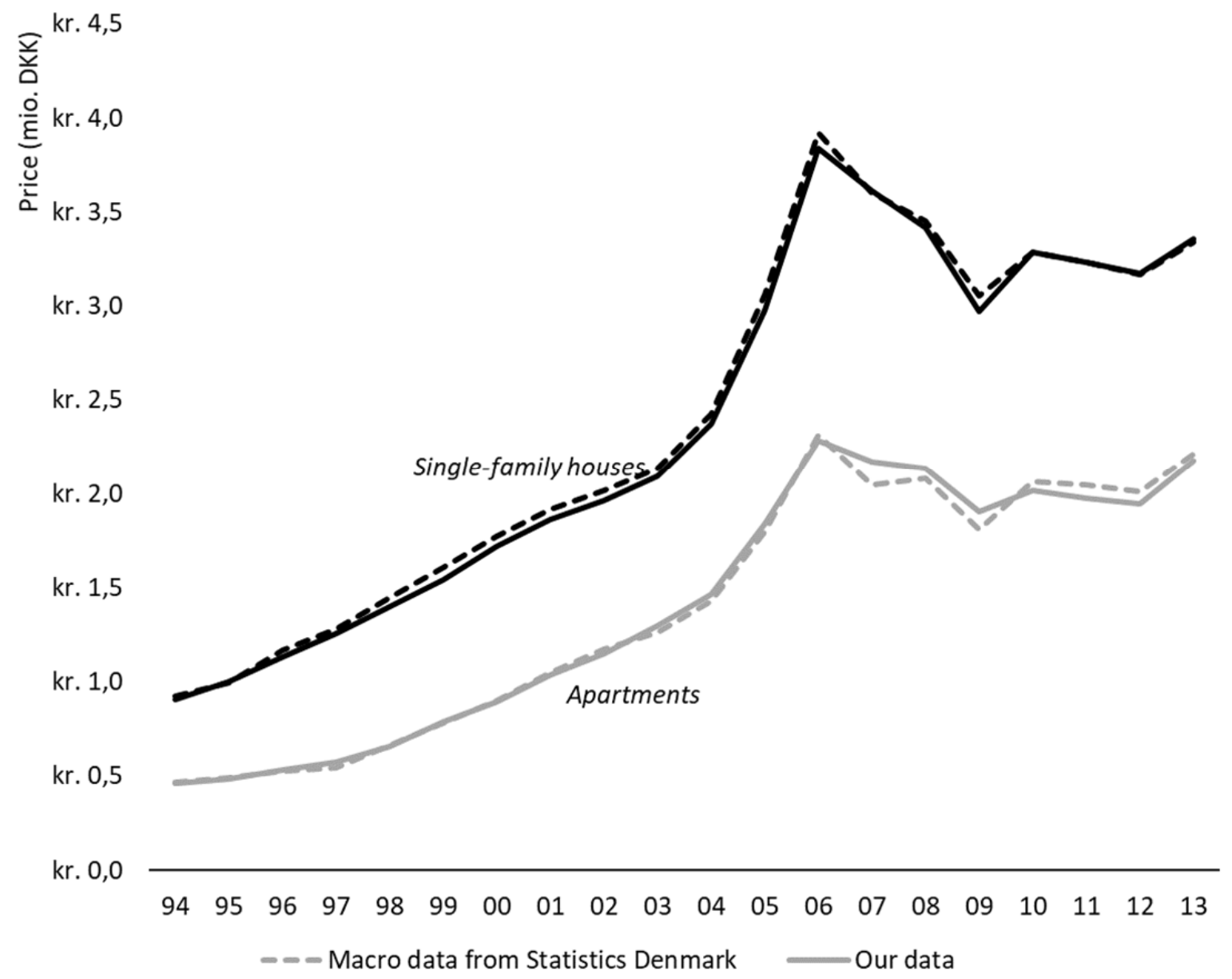

Our data also includes structural dwelling attributes extracted from the Building and Dwelling Register (BBR). These include the size of the housing unit, the number of rooms, number of bathrooms and the age of the building. Additionally, variables describing the roofing material and the type of heating system are available. BBR consists of a wide range of housing characteristics of which we use only a small part. This is because many variable definitions change over the years, hence preventing the construction of a consistent variable for the period we consider. Moreover, some important property attributes are not available in the dataset. In particular, the size of the plot is missing. Although this is of little concern for multifamily housing, for single family housing the size of the garden is an important factor of housing price. In addition, various factors determining the value of a multifamily housing are unavailable, such as whether the housing unit is facing the street or the courtyard. Our data share these 
shortcomings with those used in many other studies, but it is important to note that there are potentially important unobserved characteristics.

Table 1 shows the descriptive statistics for the dwelling attributes. ${ }^{18}$ The housing characteristics are fairly dispersed. Single family houses are in general newer and larger. Furthermore, almost all multifamily houses in the GCA have district heating appliances installed. Moreover, there is a high degree of variation in almost every quality attribute. This is very useful for the identification of the implicit prices (Sheppard, 1999).

Table 1. Descriptive statistics - dwellings for period 1994-2013

\begin{tabular}{|c|c|c|c|c|}
\hline \multirow[t]{2}{*}{ Quality attribute } & \multicolumn{2}{|c|}{ Multifamily house } & \multicolumn{2}{|c|}{ Single-family house } \\
\hline & Mean & Std. dev. & Mean & Std. dev \\
\hline Mean price (DKK M.) & 1.23 & 0.93 & 2.19 & 1.24 \\
\hline Space $\left(\mathrm{m}^{2}\right)$ & 76 & 31.5 & 126 & 39.2 \\
\hline Built before 1900 (share) & 0.13 & 0.34 & 0.03 & 0.16 \\
\hline Built between 1900-1950 (share) & 0.54 & 0.50 & 0.38 & 0.48 \\
\hline Built between 1951-1990 (share) & 0.30 & 0.46 & 0.55 & 0.50 \\
\hline Built after 1990 (share) & 0.03 & & 0.06 & \\
\hline$<3$ rooms & 0.53 & 0.50 & & \\
\hline$\geq 3$ rooms & 0.47 & 0.45 & & \\
\hline$\leq 3$ rooms & & & 0.17 & 0.38 \\
\hline 4 rooms & & & 0.37 & 0.48 \\
\hline 5 rooms & & & 0.25 & 0.44 \\
\hline$\geq 6$ rooms & & & 0.20 & 0.40 \\
\hline Listed property, share & 0.03 & 0.17 & 0.02 & 0.13 \\
\hline District heating, share & & & 0.25 & 0.43 \\
\hline Central heating, share & & & 0.67 & 0.47 \\
\hline Electric heating (and other), share & & & 0.18 & \\
\hline Detached housing, share & & & 0.69 & 0.46 \\
\hline Attached housing, share & & & 0.31 & 0.50 \\
\hline Multi-floor housing, share & & & 0.45 & 0.50 \\
\hline Number of observations & & & & \\
\hline
\end{tabular}

Table A.1 in Appendix A shows the evolution of the means for some of the quality attributes. The most remarkable is the change in the number of observations. While in the number of observations raised monotony from 1994 to 1998, decreasing from 1999 to 2003 and then again raising up to 2005, this number drops tremendously in 2006, the year when prices peaked. For apartments, the number of sales is almost halved, while the number of houses sold is reduced by a third. The number of transactions continues to remain low until around 2011 for

\footnotetext{
${ }^{18}$ Note that we have aggregated all sales from 1994-2013. This implies that some dwellings may be sold several times and that e.g. "built after 1990" will not reflect how the relation is for sales in example 2013. This does not pose a problem for our statistical model.
} 
housing and for apartments it only begins to really increase again in 2012 and 2013. These patterns are well known. Liu et al. (2014) show that number of home sales in Phoenix increased until mid-2005 (boom-period) and dropped significantly by mid-2007 (bust-period). Regarding the covariates it is noticeable that many of them are relatively stable over time. The table quotes the average size of the dwellings, which increases slightly (for single-family housing) over time, while it barely changes for multifamily housing. The other covariates exhibit similar behavior.

Finally, as will be further explained in the next section, we model urban amenities using area specific dummies. We use 169 areas designed for the purpose of the traffic modelling. With on average 7500 inhabitants per zone, this grid does not necessarily capture the micro environment around each dwelling, but still offers a reasonably fine-grained subdivision of the GCA.

\section{Empirical results}

\subsection{Measuring housing services}

This section reports the results from the rank-ordered (ro) logit procedure. We use these parameter estimates to construct a house specific measure $\widehat{H}$ of housing services/quality given in (6).

Table 2 shows two set of rologit results for single-family and multifamily housing, respectively. We estimate the two housing types separately to allow for the possibility that price developments in the two segments are significantly different, for instance because multifamily houses are closer substitutes for rental housing than single-family houses. For both single- and multifamily housing we base our estimates on the price rankings of sold dwellings in relatively small areas during limited time periods. ${ }^{19}$ The intended effect of this procedure is that our measure of housing services refers only to house characteristics, not to local public goods that vary over neighborhoods. In order to interpret the estimated coefficients, we report log-odds with respect to the other parameters.

The two estimations give the same indication in relation to size (bigger is better), age (newer is better), and being listed (listed properties are valued higher). On the other hand, singlefamily housing is valued monotonically higher with age, whereas multifamily houses built before

\footnotetext{
${ }^{19}$ See Map 1 for a map of the geographical areas.
} 
1900 are valued higher than those built from 1900-1990. This is most likely related to the building styles of multifamily houses. The vast number of 19 th century multifamily houses built around the inner ring surrounding the old city center, "Brokvartererne" (areas next to the lakes in the center of Copenhagen), is often of superior quality compared to the 1930s and 1970s apartments built in the near-city suburbs.

Table 2. Estimation results from ranked ordered logit

\begin{tabular}{|c|c|c|c|c|}
\hline & \multicolumn{2}{|c|}{ Single-family housing } & \multicolumn{2}{|c|}{ Apartments } \\
\hline Variable & Estimate & Std. err. & Estimate & Std. err. \\
\hline $\ln (\mathrm{sqm})$ & $1.883 * * *$ & 0.021 & $2.696^{* * *}$ & 0.015 \\
\hline Built before 1900 & $-0.971 * * *$ & 0.035 & $-0.887 * * *$ & 0.027 \\
\hline Built between 1900-1950 & $-0.766^{* * *}$ & 0.024 & $-0.917 * * *$ & 0.026 \\
\hline Built between 1950-1990 & $-0.647 * * *$ & 0.022 & $-0.904 * * *$ & 0.026 \\
\hline 3 rooms & & & -0.094 & 0.010 \\
\hline$\leq 3$ rooms & $-0.060 * * *$ & 0.017 & $-0.052 * * *$ & 0.013 \\
\hline 4 rooms & -0.002 & 0.013 & & \\
\hline 5 rooms & $0.064 * * *$ & 0.012 & & \\
\hline Listed property & $0.250 * * *$ & 0.031 & $0.180 * * *$ & 0.020 \\
\hline District heating & $0.089 * * *$ & 0.018 & & \\
\hline Central heating & $0.532 * * *$ & 0.014 & & \\
\hline Farmhouse & $0.530^{* *}$ & 0.251 & & \\
\hline Detached housing & $0.230 * * *$ & 0.012 & & \\
\hline Non-housing built area & $0.091 * * *$ & 0.014 & & \\
\hline Multi-floor housing & $-0.068 * * *$ & 0.009 & & \\
\hline Number of observations & \multicolumn{2}{|c|}{157,344} & \multicolumn{2}{|c|}{92,180} \\
\hline
\end{tabular}

We can now use the estimated coefficients to construct a one-dimensional measure of house quality based on equation (6). This measure is fundamental to our entire framework. Since the parameters are estimated in a discrete choice setting based on an assumption of monotonicity, the index is ordinal. This means that we can only interpret on the position of a house in the index and not the relative index distance between the houses. Furthermore, as emphasized by Rouwendal and van Duijn (2015), the index is the one that fits our statistical model best, but any monotone transformation of the index has equal validity. We have also estimated models using a subsample of quarterly data for the 2004-2013 (see Table B.1 in Appendix B). In order to compare the models, we interpret the estimated coefficients as preference weights. We find that the weights are generally the same with the exception of the weights associated with dummies 
indicating number of rooms that are significantly more negative in the model estimated on the quarterly data for the 2004-2013.

\subsection{The implied distribution and development of housing quality across Copenhagen}

In this section, we report the computed quality index $\widehat{H}$ and map its distribution over space and time. Figure 3 shows the evolution of average nominal prices and average quality of houses sold for multifamily houses and single-family houses, respectively. For multifamily houses, prices and quality were fairly uncorrelated from 1994 to 2006 when prices peaked - quality remained constant from 1997-2006, while price increased 4-fold. From 2007 the picture changes, while prices dropped $25 \%$, the quality of sold apartments spiked and when the prices increased in 2010, the average quality dropped to the 2006 level. The divergent evolution of price and quality at the time of the bubble is likely an indication of more volatile prices compared to the average price index indicates. ${ }^{20} \mathrm{We}$ see the same for single-family houses. Moreover, the quality of sales kept increasing after the crisis, indicating that the mild price recovery from 2009-2013 might in fact be higher.

Map 1 shows the average quality of single-family and multifamily houses, respectively, across the considered geographical zones (see Appendix C for area map). High quality singlefamily houses are concentrated in Frederiksberg (an enclave within the municipality of Copenhagen) and along the Øresund coast north of the city. Low quality houses are spread throughout most of south east of the inner city (Amager with the exception of Dragør) and the outer circle of the inner city. Average quality single-family houses are most predominant in the western suburbs, while the northern suburbs are predominantly high quality (although less than Frederiksberg). For apartments the picture is roughly the same, the old city center of Copenhagen and Frederiksberg is of higher quality than the inner circle of the inner city "Brokvartererne". Amager is completely divided between the old working class eastern part and the newly developed areas, "Ørestad", in the western part of the island.

\footnotetext{
${ }^{20}$ Case and Shiller (1989) find also volatile prices. They also show that a significant share of the volatility in individual house prices is idiosyncratic. More aggregated price indexes, e.g. city-wide indices are less volatile, see e.g. Flavin and Yamashita (2002).
} 
Figure 3. Evolution of prices and quality 1994-2013

a) Multifamily houses

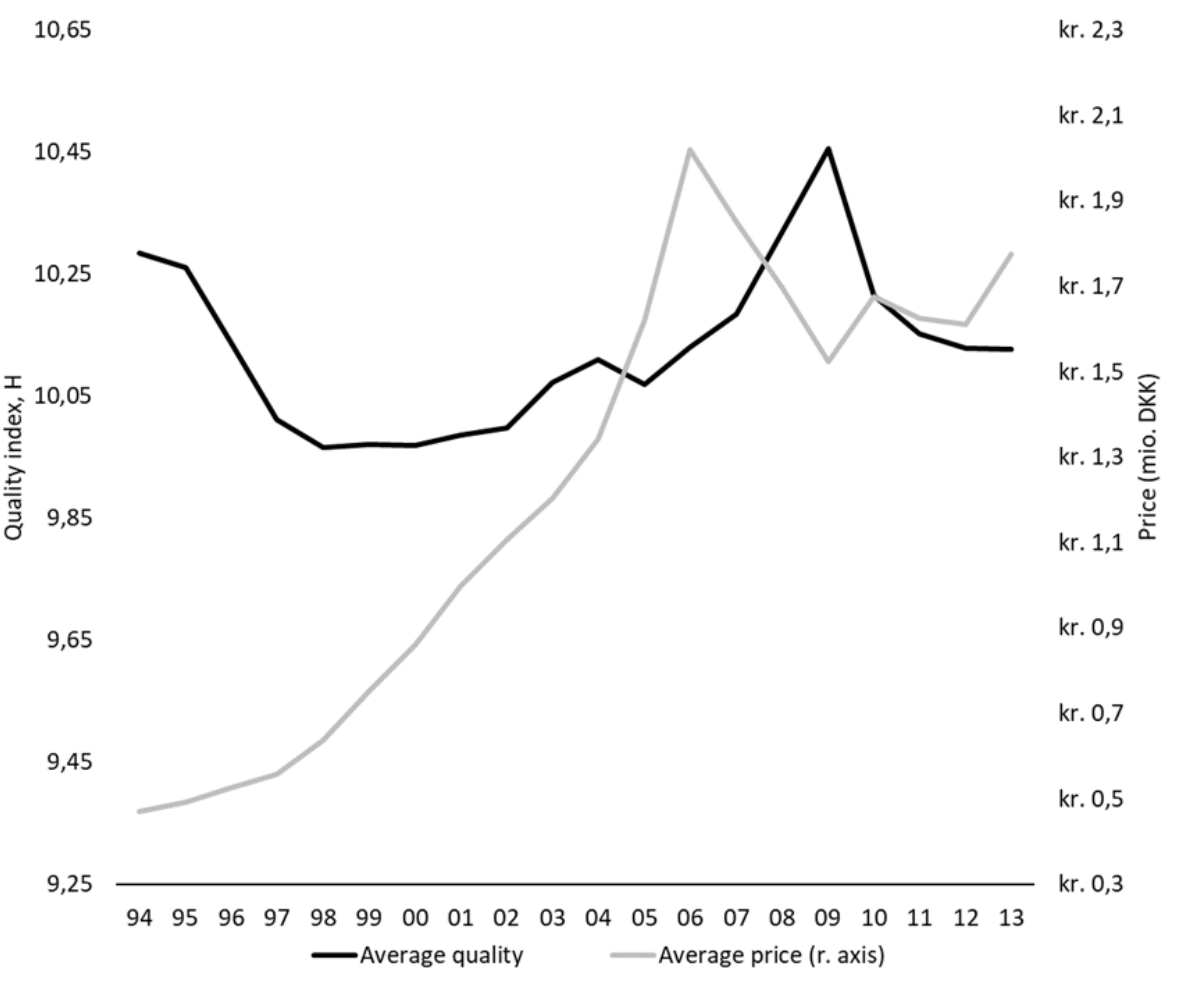

b) Single-family houses

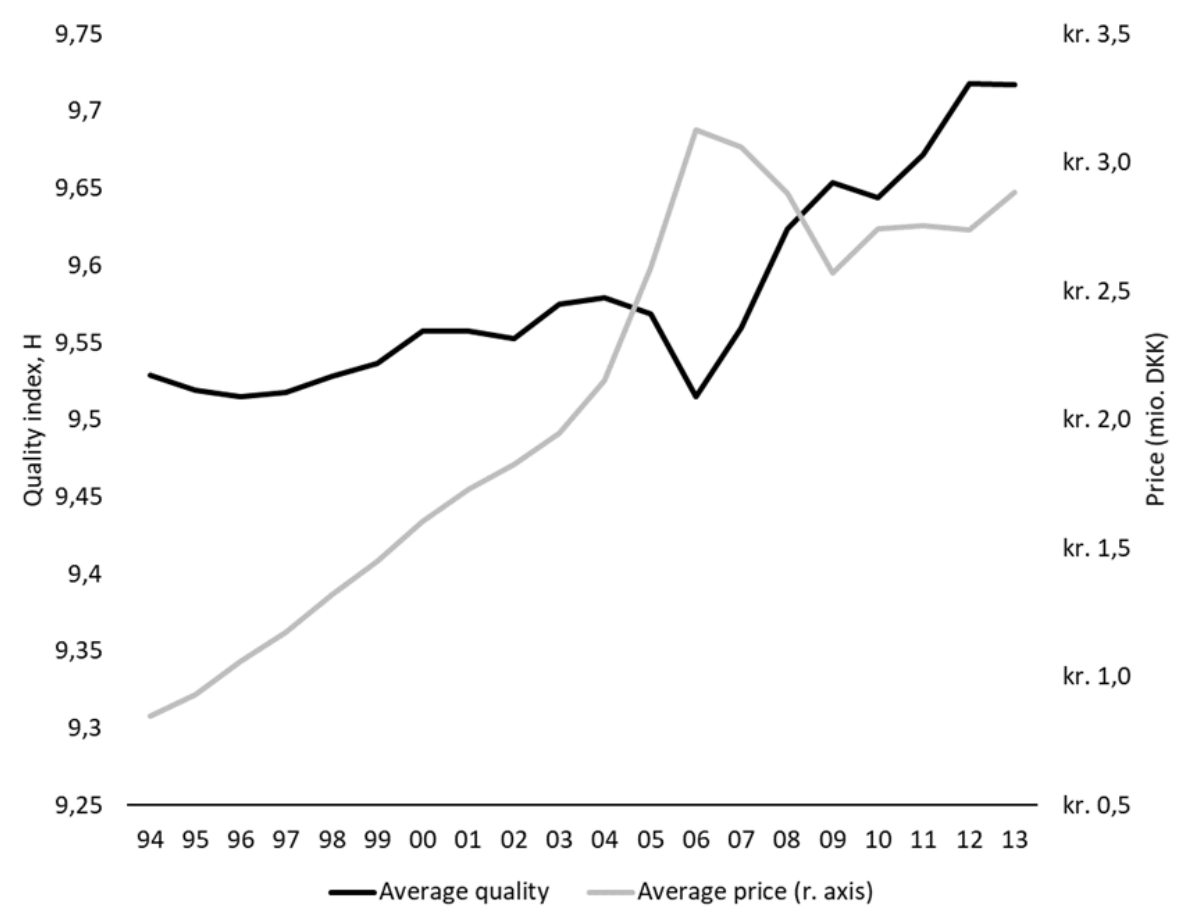


Map 1. The average quality

a) Multifamily houses

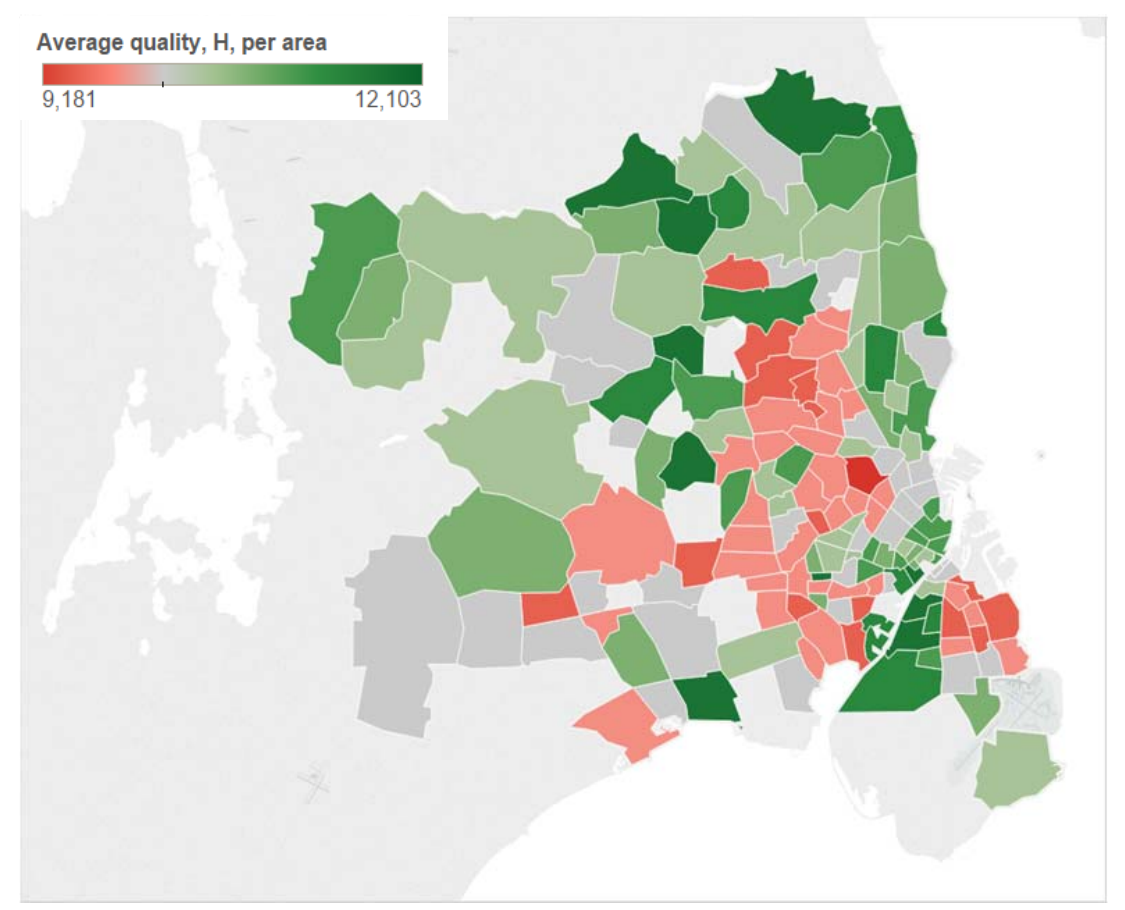

b) Single-family houses

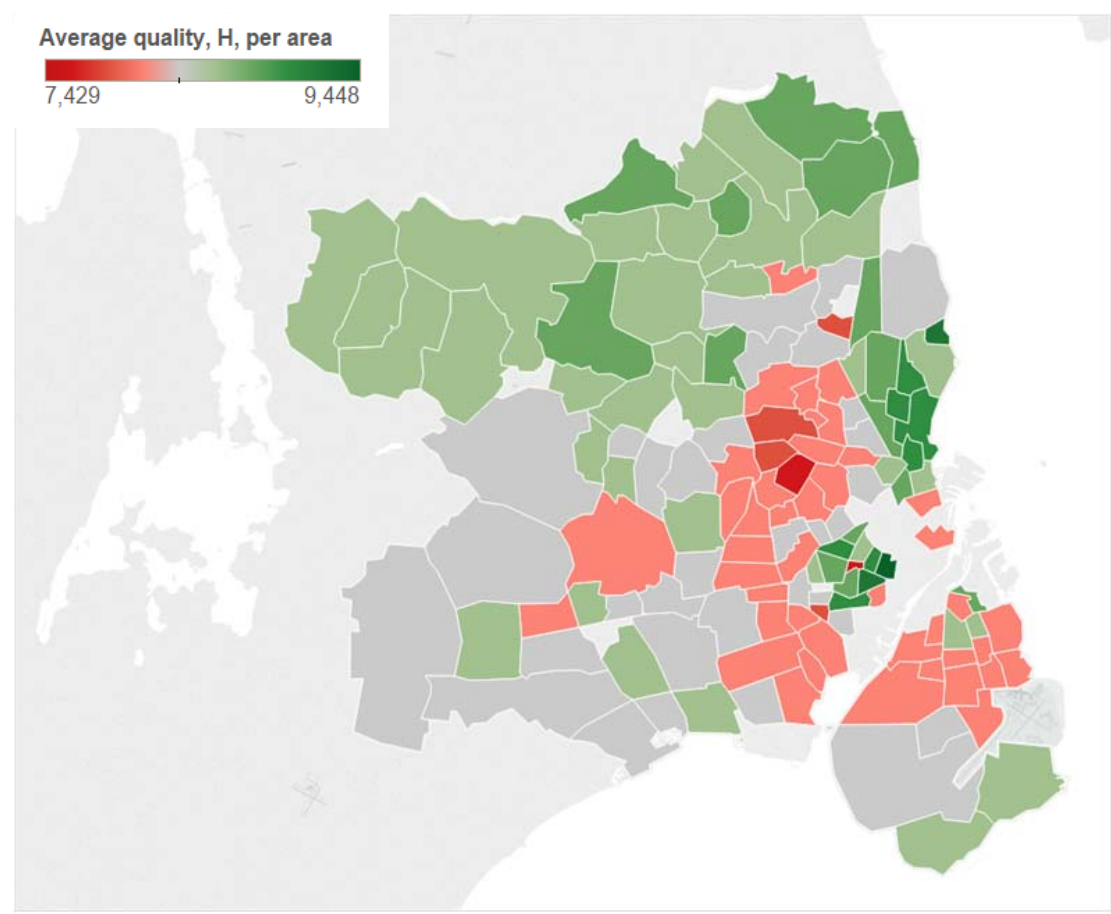

Note: see Appendix C for area map. 
For both single-family and multifamily houses, quality is therefore not uniformly distributed across the considered area. The homes in the posh areas in Frederiksberg and northern Copenhagen are of higher quality than in the working-class western parts of the city.

We now estimate the relation in equation (7) using CPAR framework for a specific quality level over time to test the constant unit price assumption. We use normal kernel function. The choice of kernel bandwidth is central to the local regression (Altman, 1992) and the literature describes appropriate methods for choosing the bandwidth (see e.g. Fan and Gijbels, 1996, and Härdle, 1993). In the present study we apply the Silverman's rule to choose the bandwidth $(h=0.01){ }^{21}$

Figure 4. Estimate of $\gamma$ for average quality level, multifamily housing, 1994-2013

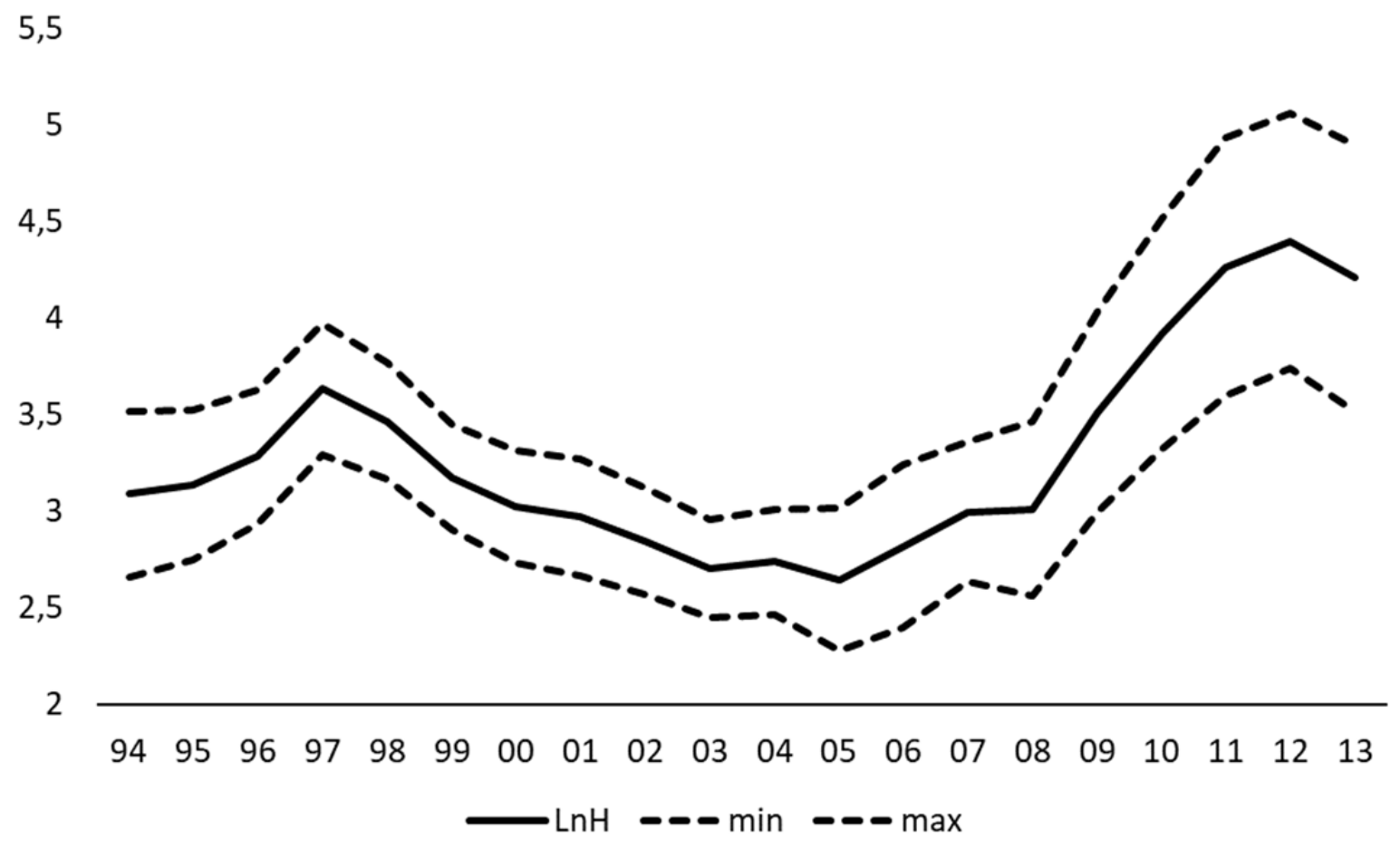

The return on quality for a specific quality level, $\gamma$, has to be constant over time for this assumption to hold. This test is conducted by visual inspection, see figure 4 . We see that the return on quality is significantly non-constant across time, and the constant unit price assumption remain robust.

${ }^{21}$ We also applied Epanechnikov kernel function and experimented with different values of $h$. The results 
is thereby rejected. ${ }^{22} \mathrm{We}$ also conducted the test of constant unit price assumption proposed by Rouwendal and van Duijn (2015). The constant unit price assumption is rejected by this test as well, see Appendix D.

\subsection{Empirical application: the housing market in Copenhagen and the financial crisis}

We now apply our constructed local price indices to investigate how the different quality segments have evolved over time. The Greater Copenhagen area has underwent some fundamental changes the last 20 years. By using the local price indices, we can see if these changes have had a uniform impact on the housing market.

We run the CPAR regression with area-dummies. For the unit price test, we looked at differences in logs, but now we are interested in the actual indices. We therefore apply exponential transportation to reach a price index with $1994=100$ (we also multiply with 100). This gives us five local median price indices for single-family houses and apartments that we have illustrated in figures 5.a and 5.b. We see that the price developments are significantly different across quality.

In general, the different price indices follow roughly the same trend, house prices rose steadily from 1994 to 2003 followed by a sharp increase from 2003-2006, a sharp decrease from 2006-2009 and a small increase from 2009 to 2013. This is in line with the theoretical literature. Glaeser et al. (2008) argue that with durable housing and downward sloping market demand, housing price must fall below pre-boom levels following the collapse of a bubble. ${ }^{23}$

There are substantial marked differences in the severities of the appreciations and depreciations across the quality segments. For single-family houses, the lower quality segments appreciated more than the mean and higher quality segments from 1994-2006. This aspect was also visible in the unit price test, as the price dispersion of single-family houses decreased in that period. From 2006 on onward, the picture changes and in that period, the higher quality levels generally outperform the lower. For multifamily houses, the story is somewhat different. Very low quality apartments appreciate at a lower rate in almost the entire period, where low quality

\footnotetext{
${ }^{22}$ We also conducted the test of constant unit price assumption proposed by Rouwendal and van Duijn (2015). The constant unit price assumption is rejected by this test as well, see Appendix D.

${ }^{23}$ Hviid (2017) argues using Danish data that developments in prices of single-family houses from 2005 were in line with the presence of a house-price bubble.
} 
apartments appreciate at the highest rate of all quality levels from 1994-2006 and underperform hereafter. Mean quality, high quality and very high quality multifamily houses followed roughly the same appreciation trend from 1994-2007, but diverge from 2007-2013. Liu et al. (2014) find the same using home sales data for Phoenix. They show that prices move together across market segments (based on the house size as the stratifying measure) up to the peak of the boom in 2006 and then fell below pre-boom levels. They also find considerable differences in the price changes across different quality segments. ${ }^{24}$

Figure 5. Price indices for different quality levels, 1994-2013 (1994=100)

\section{a) Multifamily houses 1994-2013}

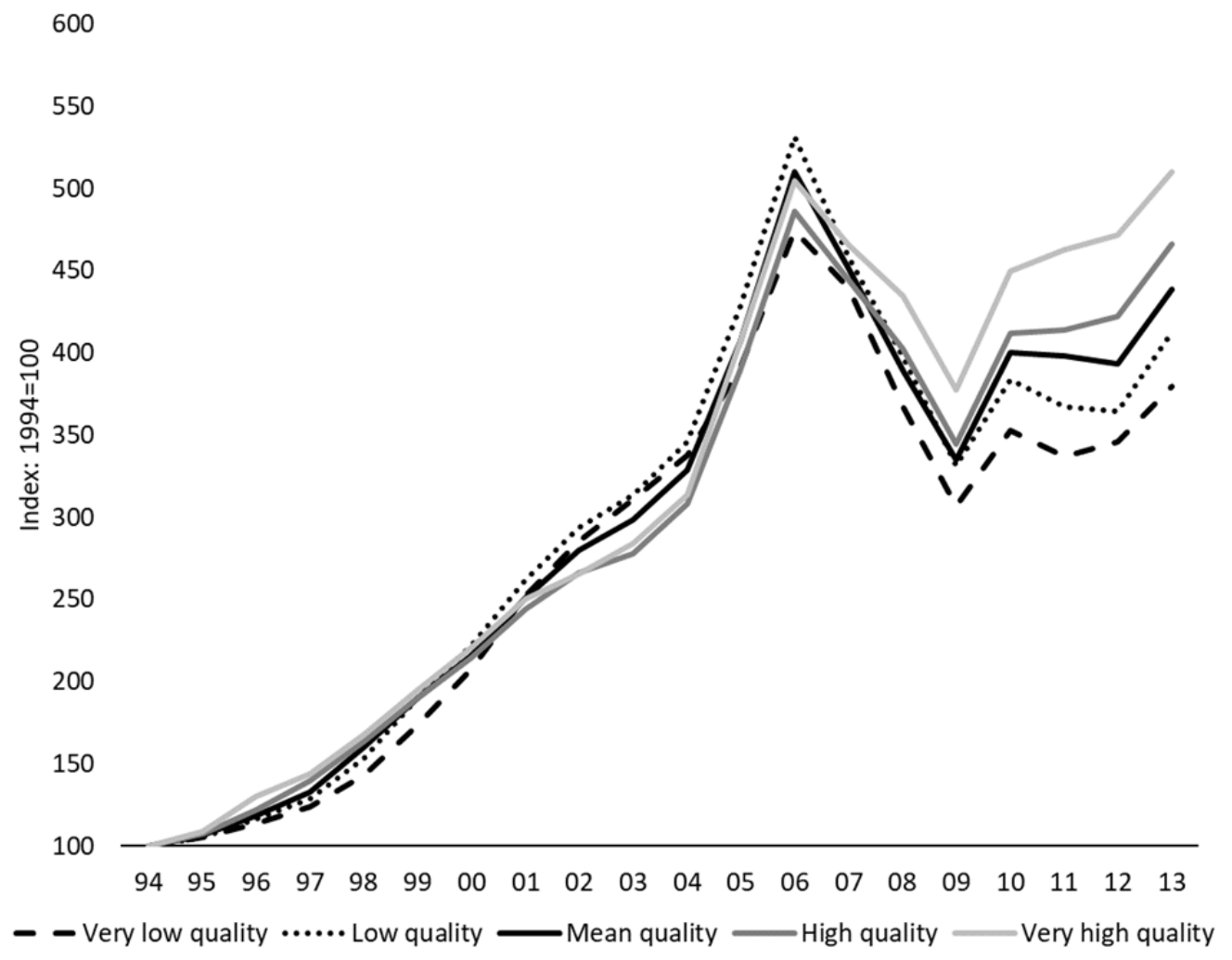

\footnotetext{
${ }^{24}$ Liu et al. (2014) offer the post-crash exit of speculative developers as the main explanation of the divergence in relative prices. They argue that relative prices should remain constant when the housing market is growing and speculative developers are building new homes. However, they only consider the supply side of the market and focus only on the new construction.
} 


\section{b) Single-family houses 1994-2013}

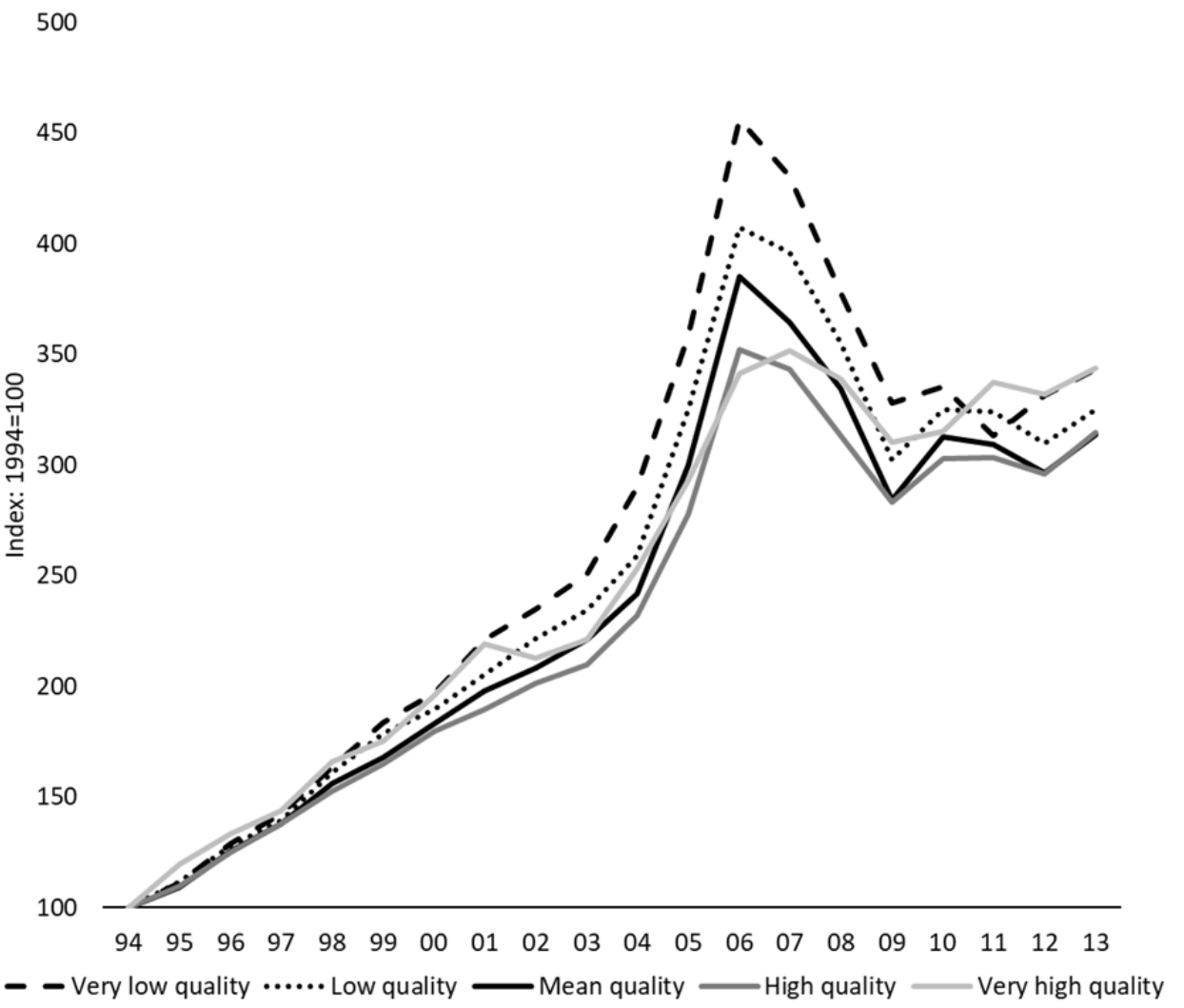

From this point on, we focus on the price developments from 2004 to 2013. When we evaluate the different price indices, we focus on three epochs from 2004-2013, a boom epoch, a bust epoch and a recovery epoch. ${ }^{25}$ We benchmark these indices up against an average and median sales price indices.

Table 3 shows the price developments for different quality levels for single-family and multifamily houses. The top half of Table 3 shows the price developments for single-family houses. In all three periods, the price developments for single-family houses exhibit variation across the quality space. In the boom epoch (2004-2006), mean and lower quality houses appreciated more than above quality houses and in the bust period the mean and lower quality houses depreciated more than above mean quality. The very high quality houses increased $35 \%$ in the boom period and fell $9 \%$ in the bust period (2006-2009). In contrast, the mean quality

${ }^{25}$ A boom epoch can be a bubble driven by unrealistic buyer expectations of future returns. 
houses appreciated by 59\% and fell 26\%. Additionally, the recovery (2009-2013) had a very heterogeneous impact on the housing market. Very high quality house prices increased by $11 \%$, mean quality house prices increased by $10 \%$ and very low quality houses increased by $5 \%$ in the period.

Table 3. Price developments over quality for three different periods

\begin{tabular}{|c|c|c|c|c|}
\hline & Quality level & $\begin{array}{c}\text { Boom } \\
2004-2006\end{array}$ & $\begin{array}{c}\text { Bust } \\
2006-2009\end{array}$ & $\begin{array}{c}\text { Recovery } \\
2009-2013\end{array}$ \\
\hline \multirow{7}{*}{ 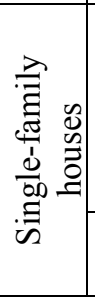 } & Very low quality (mean -2 std. dev.) & $57 \%$ & $-28 \%$ & $5 \%$ \\
\hline & Low quality (mean - 1 std. dev.) & $57 \%$ & $-26 \%$ & $8 \%$ \\
\hline & Mean quality & $59 \%$ & $-26 \%$ & $10 \%$ \\
\hline & High quality (mean + 1 std. dev.) & $52 \%$ & $-20 \%$ & $11 \%$ \\
\hline & Very high quality (mean $+2 \mathrm{std}$. dev.) & $35 \%$ & $-9 \%$ & $11 \%$ \\
\hline & Avg. sales price & $61 \%$ & $-22 \%$ & $9 \%$ \\
\hline & Median sales price & $53 \%$ & $-20 \%$ & $13 \%$ \\
\hline \multirow{7}{*}{ 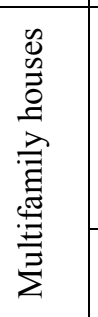 } & Very low quality (mean -2 std. dev.) & $40 \%$ & $-35 \%$ & $24 \%$ \\
\hline & Low quality (mean - 1 std. dev.) & $54 \%$ & $-38 \%$ & $24 \%$ \\
\hline & Mean quality & $55 \%$ & $-34 \%$ & $31 \%$ \\
\hline & High quality (mean + 1 std. dev.) & $58 \%$ & $-29 \%$ & $35 \%$ \\
\hline & Very high quality (mean +2 std. dev.) & $61 \%$ & $-25 \%$ & $35 \%$ \\
\hline & Avg. sales price & $61 \%$ & $-22 \%$ & $22 \%$ \\
\hline & Median sales price & $54 \%$ & $-26 \%$ & $20 \%$ \\
\hline
\end{tabular}

There are two fundamental issues with the average and median sales price indices. Firstly, they mask an underlying heterogeneity. Secondly, they do not account for quality fluctuations. The second issue is very apparent in table 3 since the average sales price index indicate an average appreciation of $61 \%$ in the boom epoch, where all of the local quality indices appreciated by less than $61 \%$. Additionally, the median sales price index is higher than all of the local price indices in the recovery epoch.

The second half of Table 3 shows price developments for the multi-family house. Here the higher quality houses outperformed the lower quality houses in all three epochs. In the boom period, higher quality multifamily houses appreciated the most, in the bust period higher quality multifamily houses depreciated the least and in the recovery period higher quality multifamily houses appreciated the most. The differences between the price appreciation/deprecation rates are remarkable. For example, the difference in appreciation between very high and very low quality multifamily houses was $21 \%$-points in the boom epoch. Piazzesi and Schneider (2016) show also that relatively cheaper houses experienced a stronger boom-bust compared with 
houses that are more expensive. ${ }^{26,27}$ This is not different from the empirical evidence based on the US data. Tsatsaronis and Zhu (2014) show that during the 2000s houses in high quality segments of U.S. housing markets appreciated less than low quality segments. ${ }^{28}$

The average sales price index for multifamily houses is consistently not in line with the local price indices. In the boom period, the absolute deviation between average sales price index and the local is $0-21 \%$-points across quality, in the bust period the absolute deviation is in the range of 3-16\%-points and in the recovery the absolute deviation is in the range of 2-13\%points. The average sales price index is by far the most used house price index in Copenhagen. Our results indicate that for single-family houses as well as multifamily houses, the average sales price index should be interpreted with care.

\subsection{The evolution of the housing quality and gentrification}

Neighborhood effects vary substantially across quality distribution and over time. Figure 6 shows how much more households are willing to pay for an apartment in the city center relative to the suburbs. In the years before the bust period (1994-2005), the "city premium" increased monotony for low quality segment. For high quality segment, it first increases until year 2000, decreases from 2000 to 2004, and then sharply increases until 2005. The premium for both quality segments decreased in 2009. During the recovery (2009-2013) the premium increased again. The "city premium" is also more volatile for low quality market segment.

\footnotetext{
${ }^{26}$ This pattern is different from the boom-bust in the 1970s, see Piazzesi and Schneider (2016).

${ }^{27}$ Kuminoff and Pope (2013) show that cheap land appreciated more than expensive land during the 2000s boom.

${ }^{28}$ Tsatsaronis and Zhu (2014) argue that large increases in mortgage debt together with large house prices increases caused this boom. Moreover, Piazzesi and Schneider (2016) argue that expectations played an important role during the 2000s boom because households were expecting house prices to growth at trend together with income.
} 
Figure 6. Copenhagen "premium" for apartments: the marginal willingness to pay for an apartment in the city center relative to the suburbs

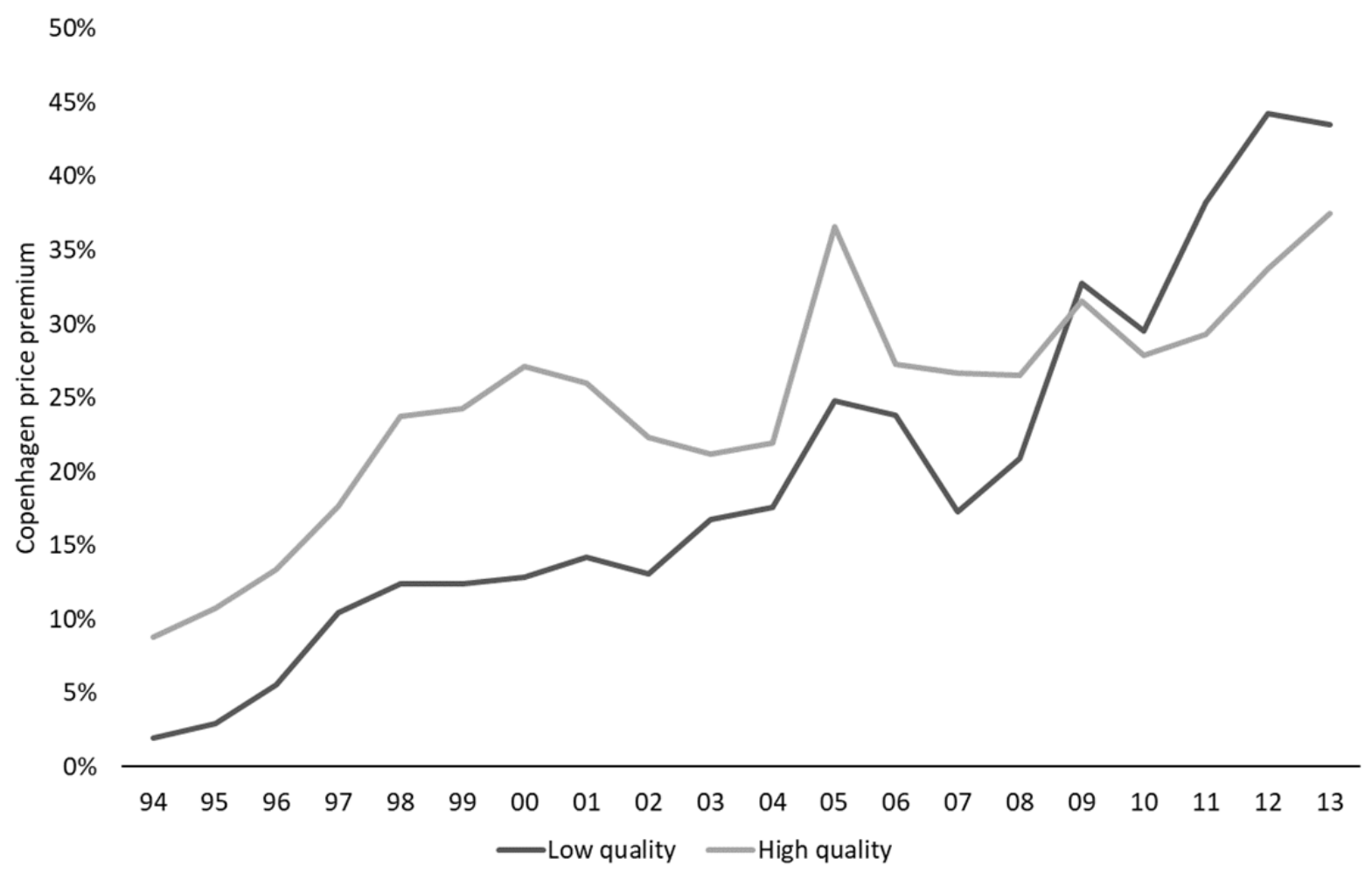

Note: Low quality is mean $-1 \mathrm{std}$. dev. and high quality is mean $+1 \mathrm{std}$. dev.

Finally, figure 7 shows the evolution of the housing price indices for different types of neighborhoods. The focus is on four neighborhood types: i) the historical city center, ii) gentrification areas (areas neighboring to the historical city center), iii) near-city suburbs, and iv) suburbs (Emdrup, Bispebjerg, Utterslev, Brønshøj, Vanløse, Husum, Valby, and Vigerslev). Figure 7 shows that in 1993 areas neighboring to the historical city center (gentrification neighborhoods) had the lowest housing price. Twenty years after, the housing price for these gentrification areas was higher compared with suburbs. This finding is consistent with Guerrieri et al. (2013) who document that gentrification matters for poorer neighborhoods that are geographically close to high-price neighborhoods within a city. 


\section{Figure 7. Evolution of the housing price indices (DKK mio.) for different area types}

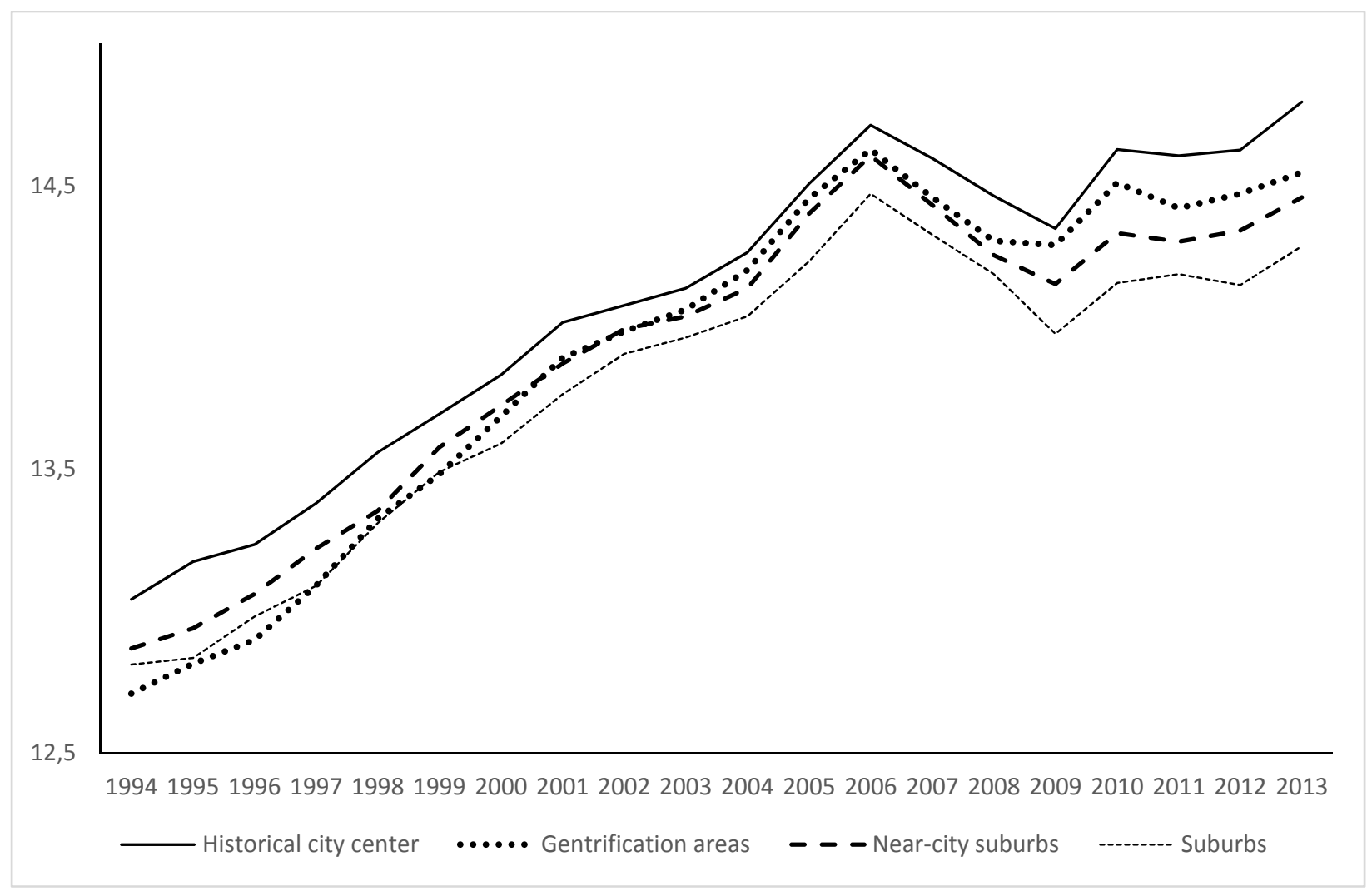

Note: The historical city center includes inner city of Copenhagen, inner Østerbro, inner Frederiksberg, and Christianshavn, ii) gentrification areas (areas neighboring to the historical city center) includes areas around the central train station, inner Vesterbro, inner Nørrebro, and inner Amager, iii) near-city suburbs include outer Østerbro, outer Nørrebro, outer Vesterbro, outer Amager, and outer Frederiksberg, and iv) suburbs include Emdrup, Bispebjerg, Utterslev, Brønshøj, Vanløse, Husum, Valby, and Vigerslev.

\section{Conclusions}

This paper investigates whether housing prices for different quality segments move proportionally over time. Our empirical results show that this is not the case. Based on the detailed data for house sales in Copenhagen in the period 1994-2013, we construct price indices for a range of different quality segments. From these indices, we show that average sales price index masks an underlying heterogeneity. This implies that the assumptions leading to the basic use of the hedonic price model on the housing market is violated. This conclusion is in line with the findings of Rouwendal and Duijn (2015). 
The empirical results suggest that the financial crisis from 2009 and onwards had a very different impact on the low and high quality housing segments. This difference is most prominent in the market for multifamily houses, where high quality dwellings have consistently seen higher price appreciations and lower price depreciations from 2004 and onwards, leading to higher price dispersion across the entire market. For single-family housing, we find that price fluctuations are highest for lower quality housing and lowest for higher quality housing. We find also that gentrification matters for poorer neighborhoods that are geographically close to highprice neighborhoods.

Our findings contribute to a general conclusion that a single price index, hedonic or simple, is misleading. The quality segment price indices give a clear indication that a major event such as the housing bubble in Denmark did not have a uniform impact on the housing market. These findings are important not only to scholars, but also to policy makers, because they may alter the need for instruments that mitigate the risk of a new housing bubble.

\section{References}

Altman, N. S., 1992. An introduction to kernel and nearest-neighbor nonparametric regression. The American Statistician, 46, no. 3, 175-185.

Bajari, P. and M.E. Kahn. 2005. Estimating Housing Demand with an Application to Explaining Racial Segregation in Cities. Journal of Business \& Economic Statistics, pp. 20-33.

Beggs, S., S. Cardell and J. Hausman. Assessing the potential demand for electric cars. Journal of econometrics, 17(1), pp. 1-19.

Bisgaard, H. 2010. Københavns Genrejsning 1990-2010. Bogværket.

Case, K. E. and R. J. Shiller. 1989. The Efficiency of the Market for Single-Family Homes. American Economic Review, 79 (1), pp. 125-137.

Fan, J and I. Gijbels. 1996, Local polynomial modeling and its applications. Chapman \& Hall, London.

Glaeser, E. L., J. Gyourko and A. Saiz. 2008. Housing Supply and Housing Bubbles. Journal of Urban Economics, 64, pp. 198-217.

Davis, M. and S. Van Nieuwerburgh. 2014. Housing, Finance and the Macroeconomy. Working paper. 
Epple, D. and H. Sieg. 1999. Estimating Equilibrium Models of Local Jurisdictions. Journal of Political Economy, 107(4), pp. 645-681.

Epple, D., L. Quintero and H. Sieg 2015. A New Appproach to Estimating Hedonic Equilibrium for Metropolitan Housing Markets. Working Paper, University of Pennsylvania.

Erlandsen,E., J. Lundsgaard and F. Hüfner, 2006. The Danish Housing Market: Less Subsidy and more Flexibility. OECD Economics Department Working Papers, No. 513. Paris: OECD Publishing.

Flavin, M. and T. Yamashita. 2002. Owner-Occupied Housing and the Composition of the Household Portfolio. American Economic Review, 92 (1), pp. 345-362.

Guerrieri, V., D. Hartley and E. Hurst. 2013. Endogenous gentrification and housing price dynamics. Journal of Public Economics, 100, pp. 45-60.

Goodman, J.L. and Ittner, J.B., 1992. The accuracy of home owners' estimates of house value. Journal of Housing Economics, 2(4), pp. 339-357.

Guerrieri, V., D. Hartley and E. Hurst. 2013. Endogenous Gentrification and Housing Price Dynamics. Journal of Public Economics, 103 (5), pp. 1664-96.

Härdle, W., 1993. Applied nonparametric regression. Cambridge University Press.

Hill, R. 2011. Hedonic price indexes for housing. OECD Publishing. doi: http://dx.doi.org/ 10.1787/ 5kghzxpt6g6f-en.

Hviid, S. J. 2017. A leading indicator of house-price bubbles. The Working Papers of Danmarks Nationalbank, no. 114.

Kahn, M.E. 1995. A revealed preference approach to ranking city quality of life. Journal of Urban Economics, 38(2), pp. 221-235.

Kiel, K.A. and J.E. Zabel. 1999. The accuracy of owner-provided house values: The 1978-1991 American Housing Survey. Real Estate Economics, 27(2), pp. 263-298.

Kuminoff, N. V. and J. C. Pope. 2013. The Value of Residential Land and Structures during the Great Housing Boom and Bust. Land Economics, 89 (1), pp. 1-29.

Landvoigt, T., M. Piazzesi and M. Schneider. 2012. The housing market(s) of San Diego. NBER working paper 17723 .

Liu, C.H., A. Nowak and S.S. Rosenthal. 2014. Bubbles, post-crash dynamics and the housing market. The Center for Real Estate and Finance Working Paper Series, 2014-001. 
McMillen, D. 2008. Changes in the distribution of house prices over time: Structural characteristics, neighborhood, or coefficients? Journal of Urban Economics, 64, pp. 573-589.

Mulalic, I., N. Pilegaard, N. and J. Rouwendal. 2016. Does improving Public Transport decrease Car Ownership? Evidence from the Copenhagen Metropolitan Area. Tinbergen Institute Discussion Paper, 15-139/VIII.

Munch, J.R. and M. Svarer. 2002. Rent control and tenancy duration. Journal of Urban Economics, 52(3), pp. 542-560.

Muth, R.F. 1960. The demand for non-farm housing. In: A.C. Harberger (ed.) The Demand for Durable Goods, Chicago, pp. 29-96.

Ortalo-Magnë, F. and S. Rady. 2006. Housing market dynamics: On the contribution of income shocks and credit constraints. Review of Economic Studies, 73, 459-485.

Piazzesi, M. and M. Schneider. 2016. Housing and Macroeconomics. NBER working paper 22354.

Piazzesi, M., M. Schneider and S. Tuzel. 2007. Housing, Consumption and Asset Pricing. Journal of Financial Economics, 83, pp. 531-569.

Roback, J. 1982. Wages, rents, and the quality of life. The Journal of Political Economy, Vol. 90, No. 6 pp. $1257-1278$.

Rouwendal, J. 1998. On housing services. Journal of housing economics, 7(3), pp. 218-242.

Rouwendal, J. and M. Duijn. 2015. Measuring diverging house prices. Manuscript.

Skaarup, M. and S. Bødker. 2010. House prices in Denmark: are they far from equilibrium? Danish Ministry of Finance Working Paper.

Sheppard, S. 1999. Hedonic analysis of housing markets. Handbook of regional and urban economics, 3, pp. $1595-1635$.

Taylor, L.O. 2003. The hedonic method. In: A primer on nonmarket valuation. Springer Netherlands, pp. 331-393.

Vestergaard, H., 2007. A short history of housing and housing policy in Denmark since 1945. In: Kristensen, H. ed. Housing in Denmark. Copenhagen: Centre for Housing and Welfare - Realdania Research.

Zabel, J.E. and K.A. Kiel. 2000. Estimating the demand for air quality in four US cities. Land Economics, pp.174-194. 


\section{Appendix}

\section{A. Additional descriptive statistics}

Table A.1: Descriptive statistics for selected variables for period 1994-2013

\begin{tabular}{|c|c|c|c|c|c|c|c|}
\hline \multirow[b]{2}{*}{ Year } & \multicolumn{3}{|c|}{ Multifamily housing } & \multicolumn{3}{|c|}{ Single-family housing } & \multirow[t]{2}{*}{$\begin{array}{l}\text { Total num. } \\
\text { of obs. }\end{array}$} \\
\hline & $\begin{array}{c}\text { Number of } \\
\text { observations }\end{array}$ & $\begin{array}{l}\text { Mean price } \\
\text { (DKK M.) }\end{array}$ & $\begin{array}{c}\text { Mean } \\
\text { space }\left(\mathrm{m}^{2}\right)\end{array}$ & $\begin{array}{l}\text { Number of } \\
\text { observations }\end{array}$ & $\begin{array}{l}\text { Mean price } \\
\text { (DKK M.) }\end{array}$ & $\begin{array}{c}\text { Means space } \\
\left(\mathrm{m}^{2}\right)\end{array}$ & \\
\hline 1994 & 6782 & 0.47 & 80 & 5028 & 0.93 & 120 & 11,810 \\
\hline 1995 & 7741 & 0.49 & 79 & 4990 & 1.02 & 125 & 12,731 \\
\hline 1996 & 9237 & 0.54 & 76 & 5103 & 1.13 & 125 & 14,340 \\
\hline 1997 & 10464 & 0.58 & 73 & 4817 & 1.27 & 125 & 15,281 \\
\hline 1998 & 10648 & 0.67 & 72 & 4591 & 1.42 & 125 & 15,239 \\
\hline 1999 & 10136 & 0.79 & 72 & 4149 & 1.56 & 125 & 14,285 \\
\hline 2000 & 9693 & 0.90 & 72 & 4876 & 1.73 & 126 & 14,569 \\
\hline 2001 & 8903 & 1.04 & 72 & 4788 & 1.86 & 126 & 13,691 \\
\hline 2002 & 8229 & 1.14 & 73 & 4452 & 1.96 & 124 & 12,681 \\
\hline 2003 & 8226 & 1.25 & 74 & 4695 & 2.08 & 126 & 12,921 \\
\hline 2004 & 9910 & 1.41 & 75 & 5224 & 2.31 & 127 & 15,134 \\
\hline 2005 & 10167 & 1.76 & 74 & 4711 & 2.77 & 125 & 14,878 \\
\hline 2006 & 6380 & 2.21 & 76 & 3291 & 3.30 & 121 & 9,671 \\
\hline 2007 & 6935 & 2.00 & 76 & 4399 & 3.23 & 121 & 11,334 \\
\hline 2008 & 5183 & 1.90 & 78 & 3777 & 3.05 & 125 & 8,960 \\
\hline 2009 & 5137 & 1.69 & 82 & 4228 & 2.76 & 127 & 9,365 \\
\hline 2010 & 5663 & 1.88 & 83 & 4997 & 2.96 & 126 & 10,660 \\
\hline 2011 & 5152 & 1.85 & 82 & 4129 & 3.05 & 126 & 9,281 \\
\hline 2012 & 6210 & 1.83 & 82 & 4821 & 3.03 & 132 & 11,031 \\
\hline 2013 & 6548 & 2.03 & 82 & 5116 & 3.18 & 132 & 11,664 \\
\hline
\end{tabular}




\section{B. Additional estimation results}

Table B.1. Ranked ordered logit estimation results using a subsample of quarterly data for the 2004-2013

\begin{tabular}{|c|c|c|c|c|}
\hline & \multicolumn{2}{|c|}{ Single-family housing } & \multicolumn{2}{|c|}{ Multifamily housing } \\
\hline Variable & Estimate & Std. err. & Estimate & Std. err. \\
\hline $\ln (\mathrm{sqm})$ & $1.883 * * *$ & 0.021 & $2.696^{* * *}$ & 0.015 \\
\hline Built before 1900 & $-0.971 * * *$ & 0.035 & $-0.887 * * *$ & 0.027 \\
\hline Built between 1900-1950 & $-0.766 * * *$ & 0.024 & $-0.917 * * *$ & 0.026 \\
\hline Built between 1950-1990 & $-0.647 * * *$ & 0.022 & $-0.904 * * *$ & 0.026 \\
\hline 3 rooms & & & -0.094 & 0.010 \\
\hline$\leq 3$ rooms & $-0.060 * * *$ & 0.017 & $-0.052 * * *$ & 0.013 \\
\hline 4 rooms & -0.002 & 0.013 & & \\
\hline 5 rooms & $0.064 * * *$ & 0.012 & & \\
\hline Listed property & $0.250 * * *$ & 0.031 & $0.180 * * *$ & 0.020 \\
\hline District heating & $0.089 * * *$ & 0.018 & & \\
\hline Central heating & $0.532 * * *$ & 0.014 & & \\
\hline Farmhouse & $0.530 * *$ & 0.251 & & \\
\hline Detached housing & $0.230 * * *$ & 0.012 & & \\
\hline Non-housing built area & $0.091 * * *$ & 0.014 & & \\
\hline Multi-floor housing & $-0.068 * * *$ & 0.009 & & \\
\hline
\end{tabular}

Note: The reference category associated with the dummies representing built time type is "built after 1990". The reference category associated with the number of rooms is ">5 rooms" for single-family housing and " 3 rooms" for appartments. The reference category associated with the heating system is "electric heating". The reference category associated with the housing area is "single-floor housing". ***, **, * indicate that estimates are significantly different from zero at the 0.01, 0.05 and 0.10 levels, respectively. 


\section{Area map}

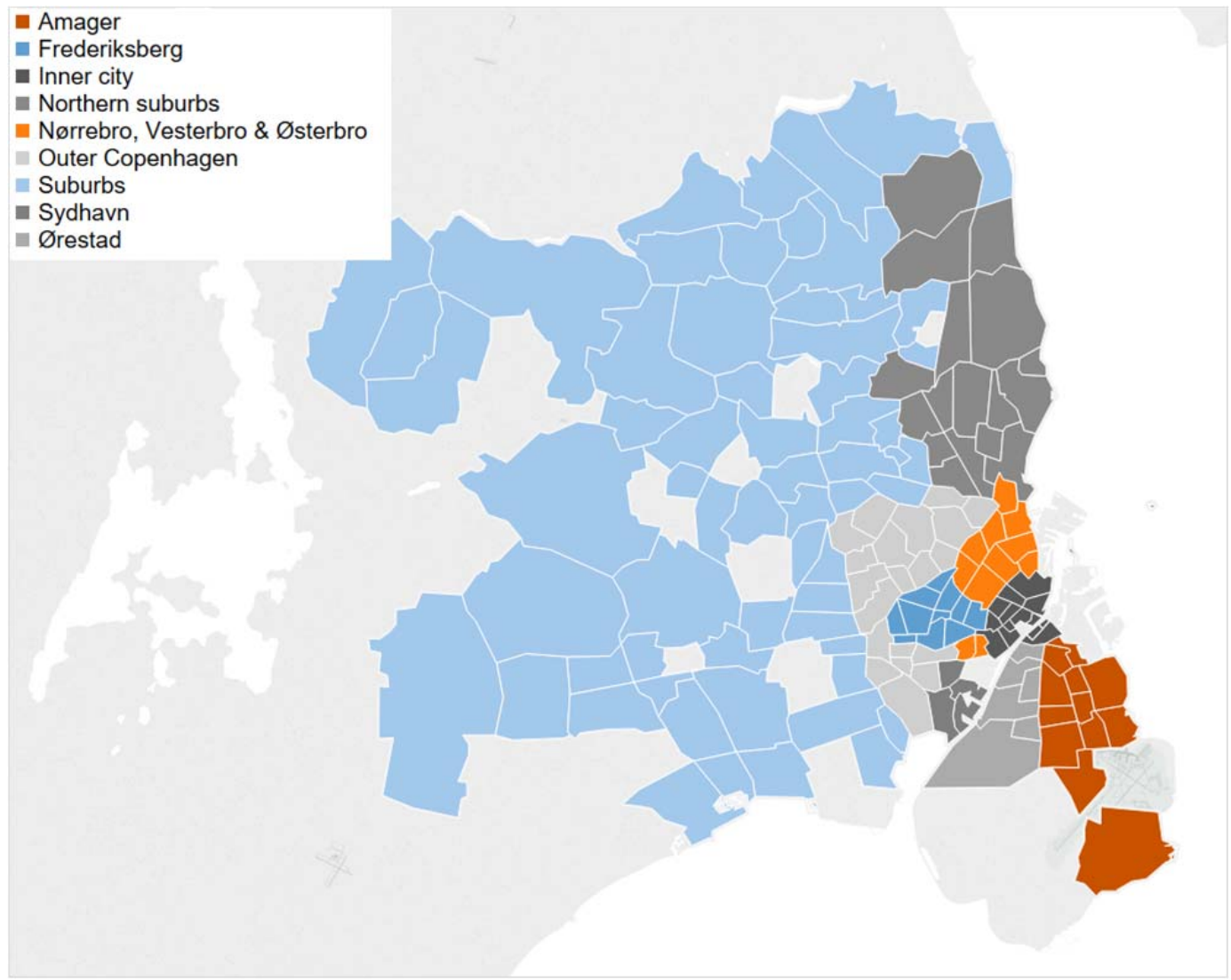

D. Test of constant unit price assumption proposed by Rouwendal and van Duijn (2015)

For the constant unit price assumption to hold, log-price differentials across quality levels has to be equal over time in order to additively separate the unit price from the quality level. To test this hypothesis, we use a visual inspection. Figures D.1.A and D.1.B depict our unit price test for single-family and multifamily houses, respectively. In the graph, the price development for the mean quality is the reference (the zero line). Graphically, this means that, for a given quality level, one can draw a horizontal line kept within the confidence band from 1994-2013. For single-family houses we can clearly reject our hypothesis for very high quality houses, for multifamily houses the hypothesis is rejected for all quality levels. We can thereby reject the hypothesis of a constant unit price. 
Figure D.1 Yearly price deviations from mean quality level 1994-2013

a) Multifamily houses 1994-2013

1

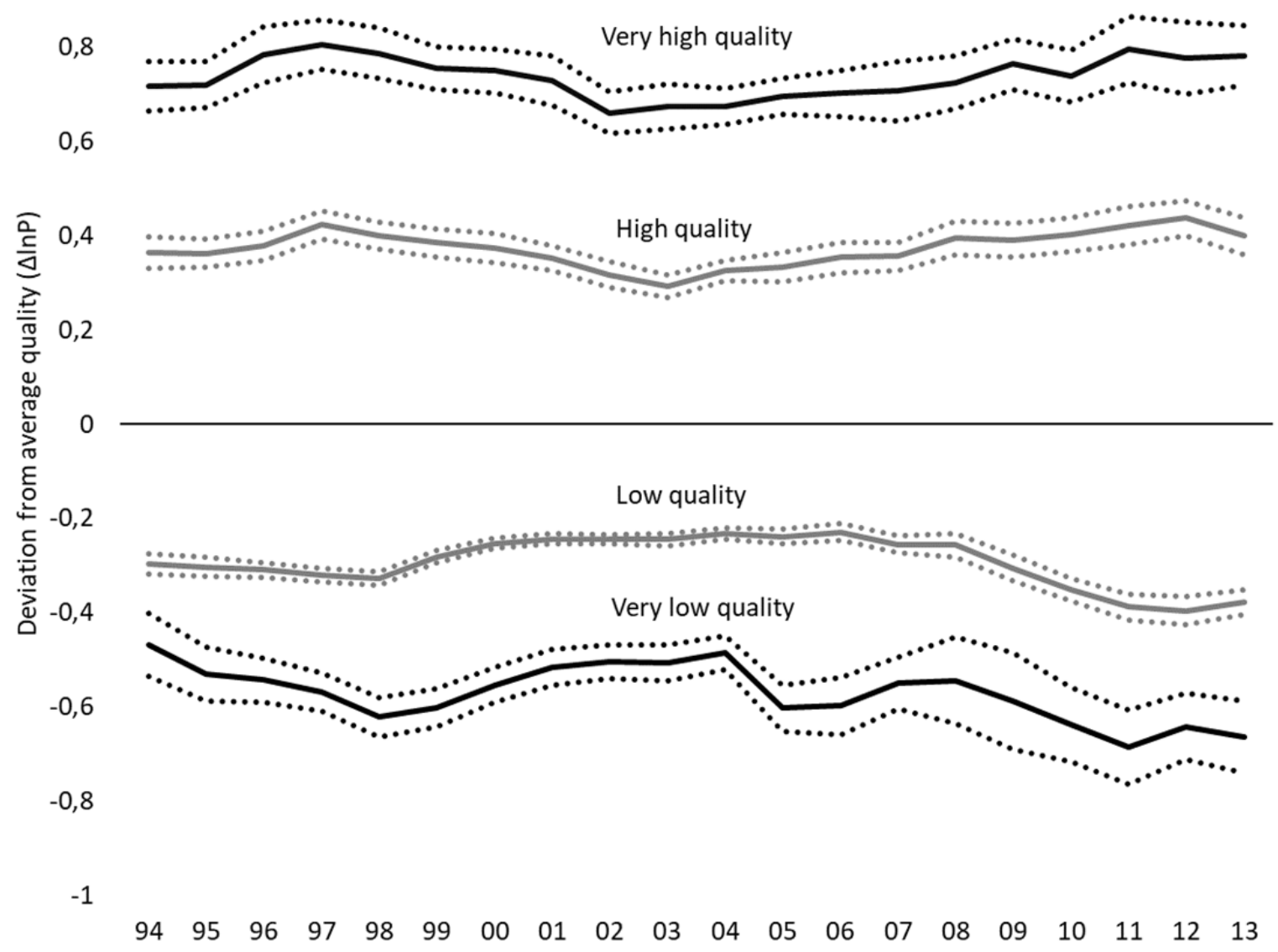




\section{b) Single-family houses 1994-2013}

1

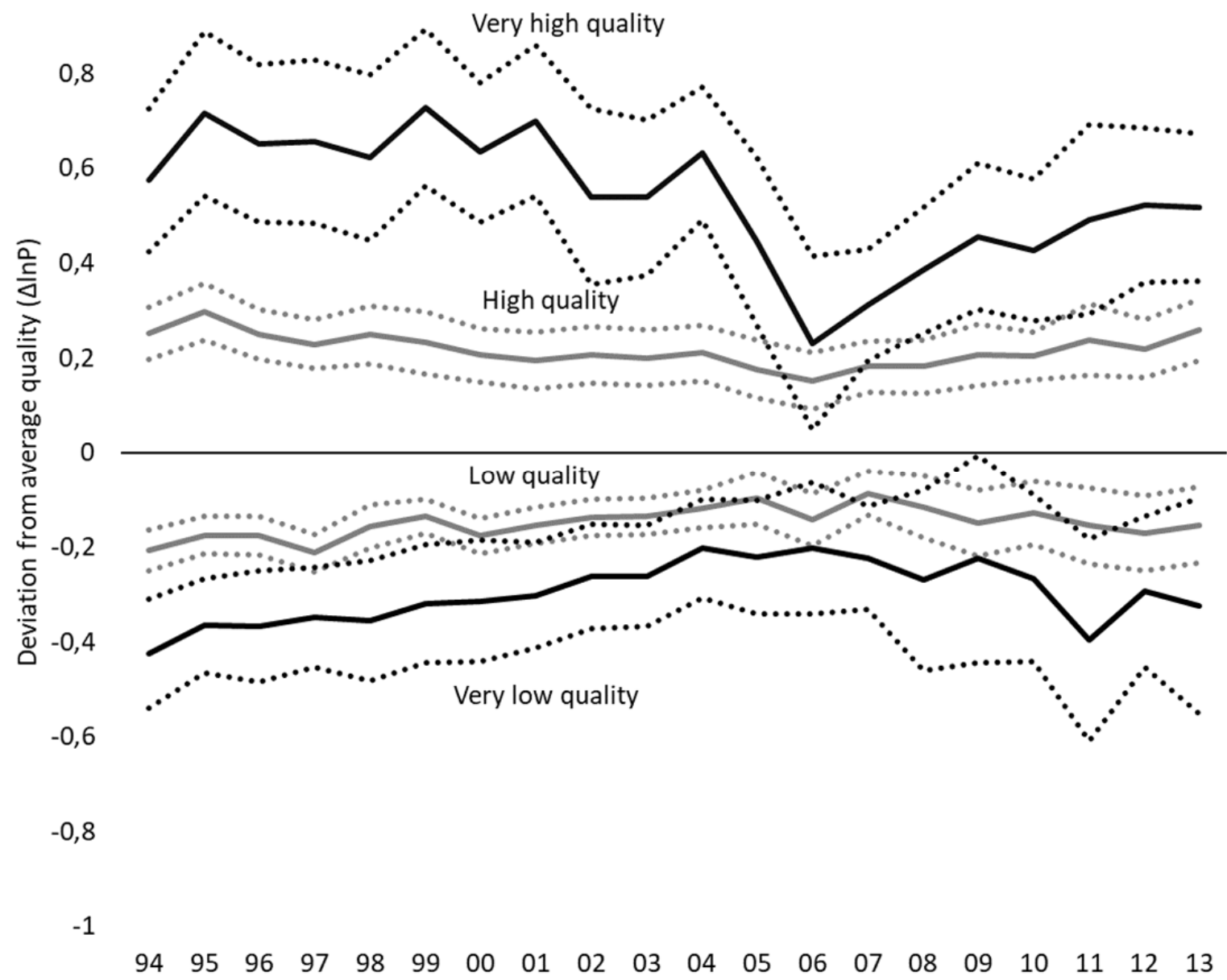

Figure D.2 shows price differentials across the mean quality level, the development of the logprice deviation between high and low quality homes and very high and very low quality homes respectively. For single-family houses we see a rejection of the unit price, due to the changes in the price differential between very high and very low quality houses. For multifamily houses, the unit price is rejected by both curves. 
Figure D.2. Yearly price deviations between different quality levels, 1994-2013

a) Single-family houses 1994-2013

1,6

1,4

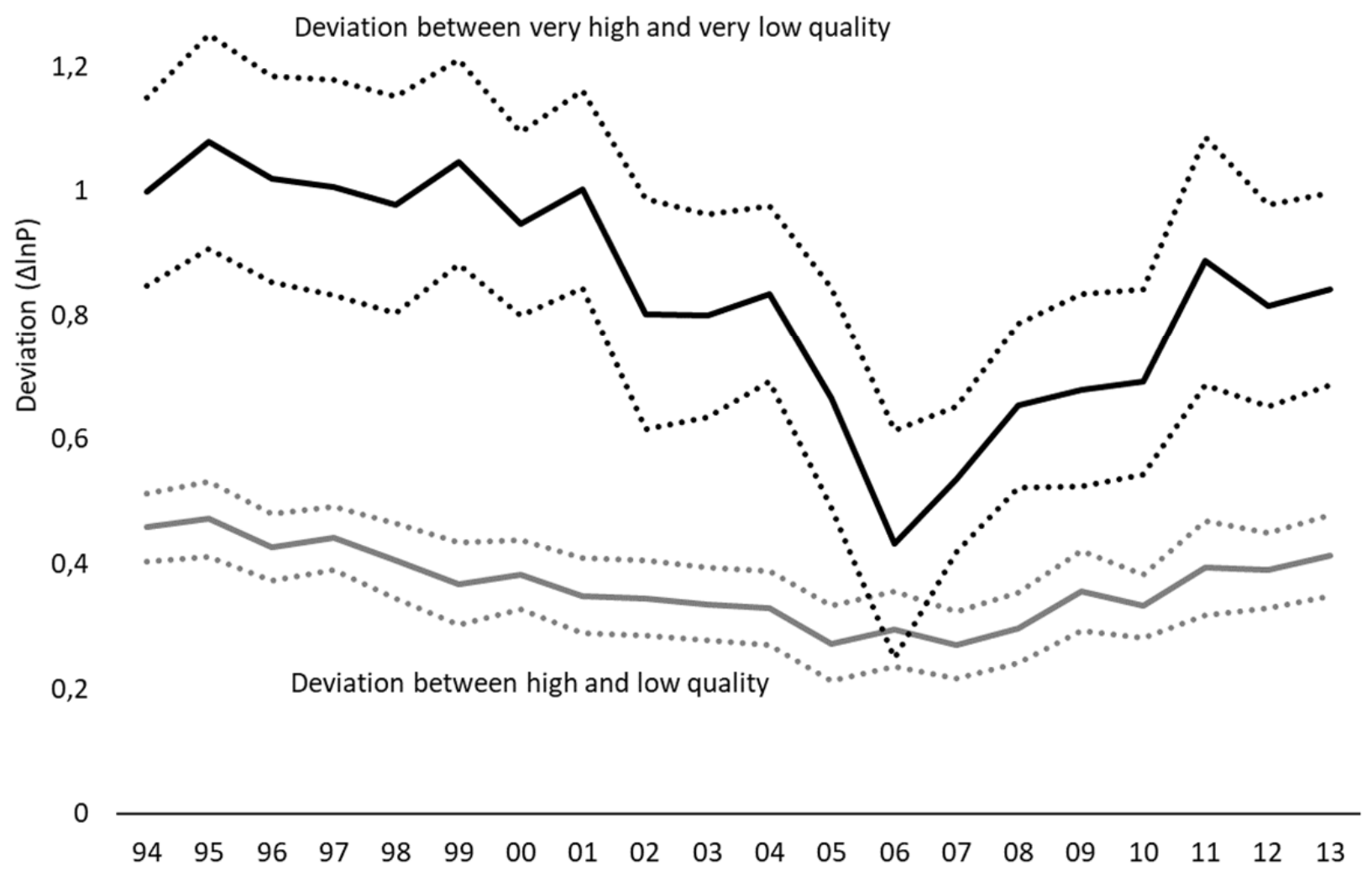


b) Multifamily houses 1994-2013

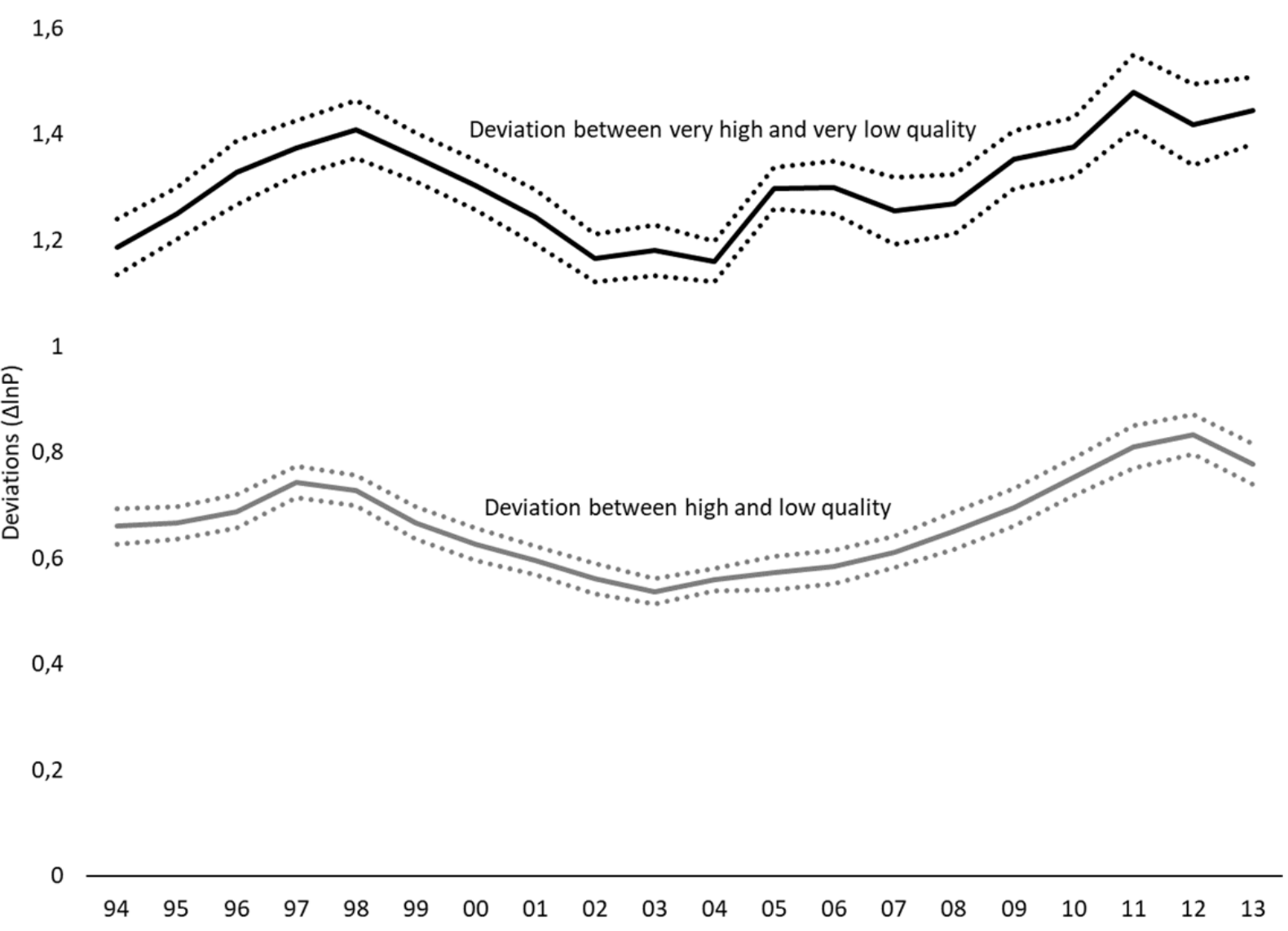

